\title{
EXPLORING INTERMEDIATE SCHOOL AGED CHILDREN'S PERCEPTIONS WITH REGARDS TO THEIR EXPERIENCES OF THEIR PHYSICAL EDUCATION CLASSES
}

\author{
By \\ Michelle Esterhuizen

\begin{abstract}
A 90-point thesis
submitted in partial fulfilment of the requirements for the Degree of MA (Applied) in Social Science Research
\end{abstract}

Victoria University of Wellington 2009 


\section{ABSTRACT}

The benefits of students participating in good quality physical education (PE) classes within their schools can impact other areas of their lives. The quantity of PE classes available to students, the level of choice, the range of activities and PE pedagogical practices need to be considered in order to maximise student participation and enjoyment levels in PE.

The overall aim of this thesis was to determine what perceptions and experiences intermediate aged children have of their physical education classes. The objectives were concerned with the quantity of physical education classes that the students received, the level of choice the students had regarding the types of activities they participated in during PE, whether the students were aware of the possible association between physical fitness and their academic performance and whether the students felt they had an extensive variety of activities available to participate in during their physical education classes.

This research utilised a survey based methodology, employing the use of a questionnaire that was completed by a total of 336 children, aged between 11 and 13 years from one Waikato Intermediate School. The findings suggested that the students were generally satisfied with the quality of their PE classes, but they recommended that some adjustments are made to their physical education curriculum and pedagogical practices. Some of these changes, included having PE more regularly, having more choice regarding the types of activities they take part in during PE, and having more diverse types of physical activities.

A trend that emerged at the data analysis stage was the number of students, (both boys and girls), who were only interested in continuing on with participation in PE when they get older out of the fear of becoming fat. This issue and some of its consequences are discussed in more detail.

Recommendations are made about PE and for further research. The nature and scope of this case study should be seen as a stepping stone for future research into this area of interest, particularly focussing on the experiences and perceptions of the students themselves. 


\section{CONTENTS}

$\begin{array}{ll}\text { Abstract } & 2\end{array}$

Acknowledgements

List of Figures $\quad 6$

$\begin{array}{ll}\text { List of Tables } & 7\end{array}$

Chapter 1 Introduction 8

- Background and Motivation

- Defining Physical Education

- Problem Statement

- Why is this Topic so Important?

- Health and Physical Activity

- The Research Aim and Objectives

- A Brief History of Physical Education

- Pedagogy of Physical Education

- Other Possible Physical Education Concerns

- Physical Education in New Zealand

- Quantity of Physical Education

- Choice Based Physical Education Programmes

- Relationship between Physical Fitness and Academic Performance

- Range of Physical Activities

- Ethnic and Gender differences regarding Participation in Physical Activity

- Fear of Fatness 
- Philosophy, Epistemology and Theoretical Perspective

- Chosen Methodology and Method

- The Pilot Study

- My Questionnaire

- Sample Size and Data Collection

- Data Analysis

- Ethical Reflections

\section{Chapter 4}

- Profile of the Participants

- Quantity of Physical Education at School

- Level of Choice

- Physical Fitness and Academic Performance

- Range of Physical Activities

- Other Aspects Covered by the Questionnaire

- Fear of Becoming Fat

Chapter 5 Conclusions and Recommendations 76

- Recommendations to the School

- Possible Strategies and Policy Implications

- Reflections on the Research

- Recommendations for Future Research

Bibliography

81

\section{Appendices}

- Appendix 1 Information letter to School Principal 89

- Appendix 2 The Questionnaire 90

- Appendix 3 Insert in the School Newsletter 94

- Appendix 4 Results Tables 95 


\section{ACKNOWLEDGEMENTS}

Firstly I would like to thank the Waikato based Intermediate school who agreed to participate in this research project at such short notice. Without the school's assistance this research would not have been possible. I am grateful for your time and support. I sincerely hope these results will be of interest to you.

Secondly I would like to express my sincerest thanks to my supervisor, Associate Professor Jenny Neale. Without your availability, encouragement, and reinforcement I would not have been able to complete this project. Thank you for demanding the absolute best from me.

Thank you to my fellow MA (Applied) Social Science Research students for your advice, support and the much needed coffee breaks!

Lastly I would like to thank my family, in particular my Dad for all his advice, patience and wisdom. Without you and many other people, this dream of mine would never have become a reality. 


\section{LIST OF FIGURES}

Figure 1: How Teacher Development affects Student Perception

Figure 2: Differentiating between Inductive and Deductive Research frameworks

Figure 3: Diagrammatic Presentation of the Research Framework employed 


\section{LIST OF TABLES}

Table 1: Summarising the differences between Mastery and Performance Climates according to the TARGET Structure

Table 2: Age of Participants

95

Table 3: Ethnicity of Participants 95

Table 4: Quantity of PE 95

Table 5: Level of Choice 96

Table 6: Fitness and Academic Performance 96

Table 7: Range of Activities 96

Table 8: Fear of Fatness 96 


\section{CHAPTER 1: INTRODUCTION}

This case study is concerned with intermediate school students' perceptions and experiences of the physical education (PE) classes presented at their particular school. This chapter outlines the background and the motivation for this research. It identifies the relevant research questions surrounding the topic, the relationships between physical activity and health and the general research aim and research objectives.

\section{Background and Motivation}

The topic of school students' perceptions of their physical education classes became of interest to me when I first relocated from South Africa to New Zealand and attended seventh form at one of the local colleges in 2000. I was surprised to find that physical education classes were optional and that almost none of my fellow seventh form students participated in any type of physical activity, neither within nor outside of school. In South Africa it was compulsory for students of all ages to actively participate in all physical education classes and to take part in at least one extracurricular form of sport presented at the school. This was not merely a recommendation but was outlined within the school curricula. The school argued that students' overall health and increased physical fitness levels can have numerous advantageous effects on their academic performance, the relationships the students have with their peers and the students' overall quality of life (Taras, 2005).

In my view, the value of physical education and the effects thereof is an important subject area to do research on within the social sciences. But, it would appear that it is not as straightforward as Taras (2005) concluded. Authors such as Myerson (2005) and Jutel (2006) disagree with Taras' positive holistic view where participation in PE proposes a simple case of healthy body, healthy mind. In both Myerson's and Jutel's accounts, it becomes evident that for them, PE was not a contributor to overall physical fitness or healthy, well balanced lifestyles. PE was posited, by these authors, as a negative concept that led them to a number of objectionable and even harmful 
experiences. In the case of Myerson (2005) the experiences she encountered in her PE classes led to social angst, high levels of stress and to some degree even fear. Jutel (2006) described having similar discomfort and embarrassing situations within her PE classes, but despite that she managed to live a very active, well balanced lifestyle in her adulthood.

The emotions described by these authors are distressing and raise a number of questions. Were their PE teachers aware of their discomfort? Has PE pedagogical practice been improved since the 1960s? How do students of today feel about participating in their PE classes? Are they experiencing the same levels of uneasiness and anxiety?

Prior to reading the above accounts, it had not occurred to me that PE could be psychologically harmful to anyone. I was under the impression that students' participation in compulsory, good quality physical education programmes could have far reaching constructive effects on many aspects of their lives. Taras (2005) stated that participation in regular, high-quality physical education programmes could contribute to biological, social and psychological benefits. Other possible benefits according to authors such as Raviv and Low (1990) and Sanders, Field, Diego and Kaplan (2000) include that active participation in PE could lead to a decrease in depression levels and an increase in concentration levels respectively.

In my opinion the advantages of active participation in PE outweigh the possible psychological discomfort that some students might experience. I appreciate how inadequately managed and defectively structured PE classes could lead to students being uncomfortable which could cause lower levels of participation, especially amongst those students who are less coordinated, over weight and/or physically or socially impaired. Conversely properly structured and managed PE classes may increase the likelihood that the above mentioned types of students will get the optimal level of participation and even enjoyment from their PE classes.

Given the apparent advantages students can gain from active participation in regular $\mathrm{PE}$, it is difficult to understand why some schools still resist allocating regular times for good quality physical education classes within their school curriculum (Hui, 
2001). One of the contributing problems to the lack of incorporation of PE classes is the fact that it is still considered to be a peripheral or minority subject (Sparkes, Templin \& Schempp, 1990; Marshall \& Hardman, 2000 both in Petrie, 2008), and those schools that see PE in this light, are more likely to give precedence to what are seen as core curriculum subjects such as mathematics, science and language. PE is an important component of a balanced lifestyle. A well balanced individual is aware of their physical functioning (Maslow, 1971 in Esterhuizen, 1996). This type of individual participates in physical exercise on a regular basis and general physical wellbeing is regarded as important.

\section{Defining Physical Education}

It is difficult to find a precise definition of what physical education is. Schools have been found to use the term loosely and interchangeably (Nixon \& Cozens, 1952; \& Petrie, 2008). Other well known terms used for physical education are physical training (PT); phys ed, fitness, gym and sport to name only a few. The fact that the term $P E$ and these other terms are used so variably makes it very difficult to research students' perceptions as they might each define and perceive physical education differently. For the purposes of this research physical education is defined as an element of the school curriculum that is concerned with the physical development and skill acquisition in the psychomotor domain through exercise, movement and play (Petrie, 2008: 68). It is aimed at getting the students fit, preparing the students for sports events, instilling positive attitudes regarding physical fitness and general wellbeing and providing the students with a scheduled in-school time to be physically active (Petrie, 2008: 68).

Following the formulation of this working definition, one can start to focus on the possible pros and cons of it. Is it all inclusive of the types of activities students participate in during PE? Are students themselves aware of the outlined aims and objectives of their PE classes? I believe that the ways in which students define their PE classes can tell us a lot about how they perceive PE. When students fully 
comprehend the aspirations, focus and intentions of their PE classes, I believe they are better able to meet the outlined requirements. Students' perceptions and experiences of their PE classes will be constructed and formulated by the ways in which they define the subject itself.

\section{Problem Statement}

There are studies that look at aspects related to the way in which students experience physical activity. For example Lee, Fredenburg, Belcher and Cleveland (1999) looked at students' conceptions regarding gender based stereotypes with regards to the different types of physical activities boys and girls choose to participate in. Hands and Martin (2003) did an evaluative study on the introduction of a new teaching component designed to support teachers in employing a primary movement skill program. Students' knowledge, confidence and participation levels were monitored. Burrows and Wright (2004) concentrated on year 4 and year 8 students' knowledge and comprehension regarding the constituents of health in a more general sense.

The problem faced and addressed in this dissertation is that students' experiences, feelings and perceptions specifically regarding their physical education classes have not previously been explored in the way I intended to. I was interested to incorporate school students' perceptions (including their insights and observations) and their experiences (inherent knowledge and understanding) of their own physical education classes. As a result of this apparent disparity, I decided to go directly to the students to get their input and feedback with regards to the PE classes being held at their specific school.

I wanted to determine whether the students felt their physical education classes were of a good quality, with regards to the types of activities they participate in; whether the students felt they had some choice with regards to the type of activities they did in PE, whether the students felt they had enough PE classes at their school and whether the students were aware that some research suggests physical fitness levels could potentially have a positive correlation with their academic performance (Castelli, 
Hillman, Buck \& Erwin, 2007). Do the students see the value of PE for themselves and do they understand the importance of physical wellness and the consequences it has on optimal functioning?

\section{Why is this Topic so Important?}

Since most schools in New Zealand only schedule PE classes once or twice a week, ranging from 30 minutes to one hour sessions (Hamlin \& Ross, 2005), it becomes increasingly important to have good quality physical education classes in order to provide the maximum benefits for participating students. For some New Zealand children, their PE classes provide the only opportunity and time for them to actually participate in physical activities of any nature. Therefore, in my opinion, it becomes increasingly important that the PE classes offered in New Zealand schools are complying not only with international standards such as being regularly scheduled, good quality, offering wide ranging types of activities within school hours, but also meet the expectations of the students who take these classes. I think one of the many challenges is to have PE programmes that cater for all levels of fitness and for all levels of abilities and to continuously promote the importance of regular physical exercise and physical wellness in a more general sense.

Throughout the last decade or more a definite decline has become evident in the amount of time children spend on physical activities. Hamlin and Ross (2005) stated that New Zealand youth have become more sedentary in their lifestyles. They identified several barriers that prevent children from engaging and participating in physical activities which result in an increase in sedentary lifestyles. According to their study, reduced hours in PE classes at school are one of the major reasons for the reduction in the amount of time children spend on physical activity outside of school hours. One of the reasons for the decline in the time set out for PE classes in our schools, is a directly related to curriculum changes.

Hamlin and Ross (2005) indicated that there were a number of changes with regards to government education policy in New Zealand which took place during the late 
1980s that directly affected the teaching and execution of physical education and sport within schools. These changes included a general trend of deregulation, and delegating curriculum matters to individual schools, in other words schools were able to compose and structure their own PE curricula, including the timetabling of the classes (Fancy, 2004 in Hamlin \& Ross, 2005; \& Petrie, 2008). These changes affected PE practices in New Zealand schools unconstructively as a Ministry of Health study (2003 in Hamlin \& Ross, 2005) found that twenty percent of 7 to 10 year olds and ten percent of 11 to 14 year olds reported in 2002 that they received no PE classes in the week that they were surveyed. It is important to appreciate the possible effects that some of these governmental policy changes can have on the execution and pedagogical practices of PE in New Zealand schools. The Ministry of Education recognised in 2004 that this decline was a problem that needed to be addressed (Hamlin \& Ross, 2005) and it aimed to increase students' physical activity during school time by at least one hour per week over and above the then scheduled PE time.

As Hamlin and Ross (2005) pointed out, curricular change implemented by the government is merely one contributing factor to an increase in students' sedentary lifestyles. Other barriers identified by Hamlin and Ross (2005) include the changes in transportation. Fewer children are walking or cycling to school, as opposed to two decades ago and more children are making use of motorised transport (for example buses, cars and trains). Several reasons could have contributed to this particular change including the fact that students can obtain their driver's licence at an earlier age, the weather, and personal safety related concerns that have arisen in the last 20 years such as greater traffic density and fear of attack.

Hamlin and Ross (2005) stated that these types of barriers must be confronted and contested on a societal level in order to ensure that there is no further decline in the time students spend on physical activities. They warned that unless these barriers are addressed and opportunities for physical activities are improved within schools and community environments, the decline in youth physical activity will continue and ultimately our youth and effectively the New Zealand health system will suffer the consequences of their sedentary and inactive lifestyles. 


\section{Health and Physical Activity}

This section will discuss some of the far reaching effects that physical activity (or inactivity) can have on individual and even societal health. Some suggestions are made to increase physical activity both inside and outside of the school domain. The roles of the schools, in promoting physical active lifestyles, are also explored.

Hamlin and Ross (2005) pointed out that physical inactivity is causing major public health issues which could result in a number of serious, but preventable diseases. McKenzie and Kahan (2008) stated that health issues such as diabetes, heart disease and obesity should be seen as warning signs to schools to become more proactive and hands-on in increasing physical activity amongst their students. They highlighted ways in which schools can become more actively involved in increasing both the amount and the quality of physical activities for their students. These include reviewing the content and teaching of the physical education curriculum in order to ensure optimal participation, program integration with other subject areas, promoting and safeguarding active forms of transportation (such as walking or cycling to school) and increasing the availability of extracurricular physical activities at school.

David Kahan (2008) emphasised the fact that physical activity during childhood is of utmost importance. He highlighted that both parents and communities should be encouraged to promote healthy, active lifestyles amongst children. Story, Kaphingst and French (2006, in Kahan, 2008) discussed the crucial role that schools should be playing in the development of physical fitness and maintaining physically active lifestyles, since supportive parents and communities are not always available to all children. For these reasons it is evident that schools do have a responsibility to uphold and encourage both student and parent involvement within the broader area of health. Kahan (2008) stated that only 17 to 22 percent of elementary schools in the United States of America offer daily PE classes. Since these classes only accumulate 85 to 98 minutes of physical activity each week, they are falling far short of the recommended 60 minutes of physical activity per day. PE classes cannot be held solely responsible for maintaining the required activity levels amongst students, therefore Kahan encourages the adoption of Jago and Baranowski's (2004, in Kahan, 
2008) recommendations for a multifaceted approach to increasing physical activity within schools. Some of these recommendations include improvements to breaktimes by ensuring adequate time is allocated to all students, having sufficient space and equipment available for physical activity during break times as well as improving and promoting extracurricular physical activities.

Another important aspect to remember with regards to health and physical activity is that both of these aspects are dependant on lifestyle. The ways in which people are engaging with everyday life has lead to the rise in childhood obesity (Schofield, Schofield, Dickson \& Croteau, 2005). Amy Hillier (2008) pointed out that entertainment by the media (in the form of television, video games and computer games, for example) have led to an increase in inactivity especially amongst children. Hillier suggested that these technological entertainment innovations should be employed to promote healthy and physically active lifestyles amongst youth. Block (2008) and Smith (2005) suggested the introduction of iPods, emerging interactive video technology and other forms of technological equipment to the physical education curriculum as a means to disseminate healthier more active lifestyles, whilst utilizing these modern technological tools. A fun activity for example, which employs modern day technologies like the Nintendo Wii Fit programme could motivate students to learn, be physically active and be competitive whilst enjoying the originality of a modern day technological tool.

Sue Headley (2005) found that 2880 Year 4 and Year 8 students surveyed in 1998 were able to identify the concept of health as a multifaceted notion, which is dependent on multiple elements, consisting of physical, mental, social, spiritual and environmental constituents. Headley stated that this knowledge should be used by teachers and parents to encourage the process of building healthy concepts and future lifestyles amongst the students. They should know what the right types of behaviours are in order to sustain and maintain healthy, physically active lifestyles.

Sport and Recreation New Zealand's (SPARC) nationwide Push Play campaign (http://pushplay.sparc.org.nz) was established in response to a nationwide research study Obstacles to Action, (2003. See SPARC website). This study identified several barriers New Zealanders were being faced with on a daily basis which resulted in 
reduced levels of physical activity. The identified barriers included lack of time and energy, lack of support and/or encouragement from others and health problems. The Push Play campaign was therefore launched to raise awareness of the benefits of physical fitness and the need to participate in physical exercise on a daily basis. The campaign was aimed at New Zealanders of all age groups, but it did have a section called Kidzone, specifically dedicated to children. The campaign's recommended level of physical activity for children of all ages, ranging from infants and toddlers to pre-adolescent aged children (up to and including 13 year olds) is at least 60 minutes a day of moderate intensity exercise. It is important to note that these levels of activity are based on international research and guidelines. Bauman, McLean, Hurdle, Walker, Boyd, van Aalst, and Carr (2003) evaluated the Push play campaign. According to them inactivity in New Zealand is as injurious as tobacco use but public knowledge, prior to the Push Play campaign regarding the risks of inactive lifestyles was not as widely advertised in comparison.

My topic of research is therefore complex and multifaceted which includes questions about the possible lack of students' comprehension on the importance of the topic, the possible lack of advocacy from schools and the pressure on the health system including obesity-related concerns. This subject matter is important, not only with regard to children's overall health and physical wellbeing, but also with regards to the effects that their general health status and fitness levels can have on other aspects of their lives. Student's perceptions of their PE classes will give an indication of their current experiences, feelings and attitudes towards the quality of the PE regime at their particular school.

\section{The Research Aim and Objectives}

Based on the preceding discussion this thesis poses the following research question: What perceptions and experiences do intermediate school aged children have of their physical education classes? 
For the purposes of this dissertation, the following key aspects need to be identified and defined more clearly. The definitions are outlined as per the online English Encarta Dictionary (http://encarta.msn.com). Perception, as it is being utilized within this specific context, refers to the process of employing one's senses to obtain information about our contiguous surroundings or a specifically outlined situation. In other words, I am exploring the students' insights and discernments with regards to the specifically outlined topic, namely their physical education classes. Experiences, as it is being employed in this context, refer to the knowledge and skill the students have acquired through their participation in their physical education classes over time.

There are four main research objectives: firstly to ascertain what the students' perceptions and experiences are with regards to the amount of physical education they are offered at their intermediate school. Secondly to explore whether the children feel they have sufficient choices with regards to the types and variety of activities they participate in during their physical education classes. Thirdly to discuss whether the students see a correlation between their physical education classes and overall fitness levels and their academic performances. And finally to determine what the students' general perceptions and experiences towards the types of activities they participate in within their physical education classes are.

Having established why I wanted to carry out this research, the next chapter reviews the literature to provide the broader context. 


\section{CHAPTER 2: REVIEW OF THE LITERATURE}

This review chapter is structured according to the outlined aim and research objectives. I look at the history of PE and its pedagogical practices on a global basis and those practised within New Zealand. Possible concerns regarding the teachings and content of physical education have also been highlighted.

Following that, the chapter will focus on the outlined research objectives including, the quantity of PE classes presented at school, the importance of choice in physical education, the possible relationship between physical fitness levels and academic performance, and the range and diversity of physical activities within PE classes will also be discussed. Other important aspects of physical education including ethnic and gender differences and the fear that some young people have of being (or becoming) overweight and how this fear affects their physical activities will also be examined.

\section{A Brief History of Physical Education}

The history of PE has affected student perceptions and experiences of the subject. Physical Education originated predominantly in the eastern regions of the world as a pedagogical subject area of interest during the late $14^{\text {th }}$ and early $15^{\text {th }}$ centuries. According to Guedes (2007) Francois Rabelais, a French born (1400s) Renaissance humanist was said to be one of the founding fathers who aimed at integrating both academic education and physical education within the western school domain. The western world accepted this integrated approach of education thousands of years after the east had already incorporated physical education as an integrated part of their school curriculum (Guedes, 2007).

Nixon and Cozens (1952) stated that the introduction of PE to the American education system is a relatively new concept. Real progress towards the inclusion of PE in the 
education structure only happened after the termination of the Civil war. The first appearance of PE programmes materialised in American colleges between 1850 and 1860. The introduction of PE to the public schooling system did not occur till some time after this (Nixon \& Cozens, 1952). Lipping (2003) found that a dramatic increase in the number of PE classes in the United States of America occurred between 1900 and 1930. According to him, numerous factors were involved in this sharp increase including industrialization, colonization and urbanization. Between 1900 and 1930 several important changes occurred in American public education, such as the introduction of compulsory schooling and the banishment of child labour. The accumulation of these social phenomena also affected the ways in which PE was presented, which included schools being more focussed on sport and play activities in general (Lipping, 2003).

In New Zealand the origins of physical education can be traced to the sophisticated and coordinated physical activities of Māori individuals (Stothart, 1974). Complex games and trainings for warfare were developed long before contact was initiated by the Europeans. As the regularity of European contact increased, Māori quickly adapted and learned European games and physical activities. New Zealand children were not obliged to attend school until the passing of the Education Act in 1877. During these early times, no provisions were made for children to take part in any forms of organised physical activities at school. The Education Act in 1877 gave the first official recognition of physical training in New Zealand schools, although it was still mainly focussed on the military drill (Stothart, 1974). One of the most influential people in the development of PE in New Zealand schools was Oscar David (Stothart, 1974). Swiss born, he came to New Zealand from Melbourne, Australia, in 1878 and introduced the philosophy of physical education to the education system, even before it was part of the official school curriculum.

The Education Amendment Act (1912) (Stothart, 1974) saw the introduction of a Director of Physical Education namely Royd Garlick. He introduced the English Syllabus of Physical Exercises and appointed numerous physical instructors around the country to instruct teachers on the implementation of the new syllabus. Consequently PE became more widespread and common within New Zealand schools. 
From this brief overview of the development and history of PE, it is evident that history itself has shaped the ways physical education is practiced both within and outside of New Zealand (Lipping, 2003). It is important to know which past factors have had effects on PE, so that we can make predictions about its future. Today the focus is much more internal, as PE has become individually based and focused (Lipping, 2003). Physical education has been created and changed by political outcomes, cultural manipulations and social transformations.

\section{Pedagogy of Physical Education}

What constitutes high-quality or inferior pedagogical PE practices? Which pedagogical practices are not acceptable? How does the pedagogy of PE influence the levels of active student participation? How does the pedagogy of PE shape student perceptions and experiences of their PE classes? These questions outline the structure of this section.

Guskey (1985, in Petrie, Jones \& McKim, 2007) formulated a flowchart that indicated the effects of pedagogical practices on student attitudes and beliefs. Figure 1 is an adaptation of that and it illustrates the importance of continual staff developments and how it can affect student perceptions. 


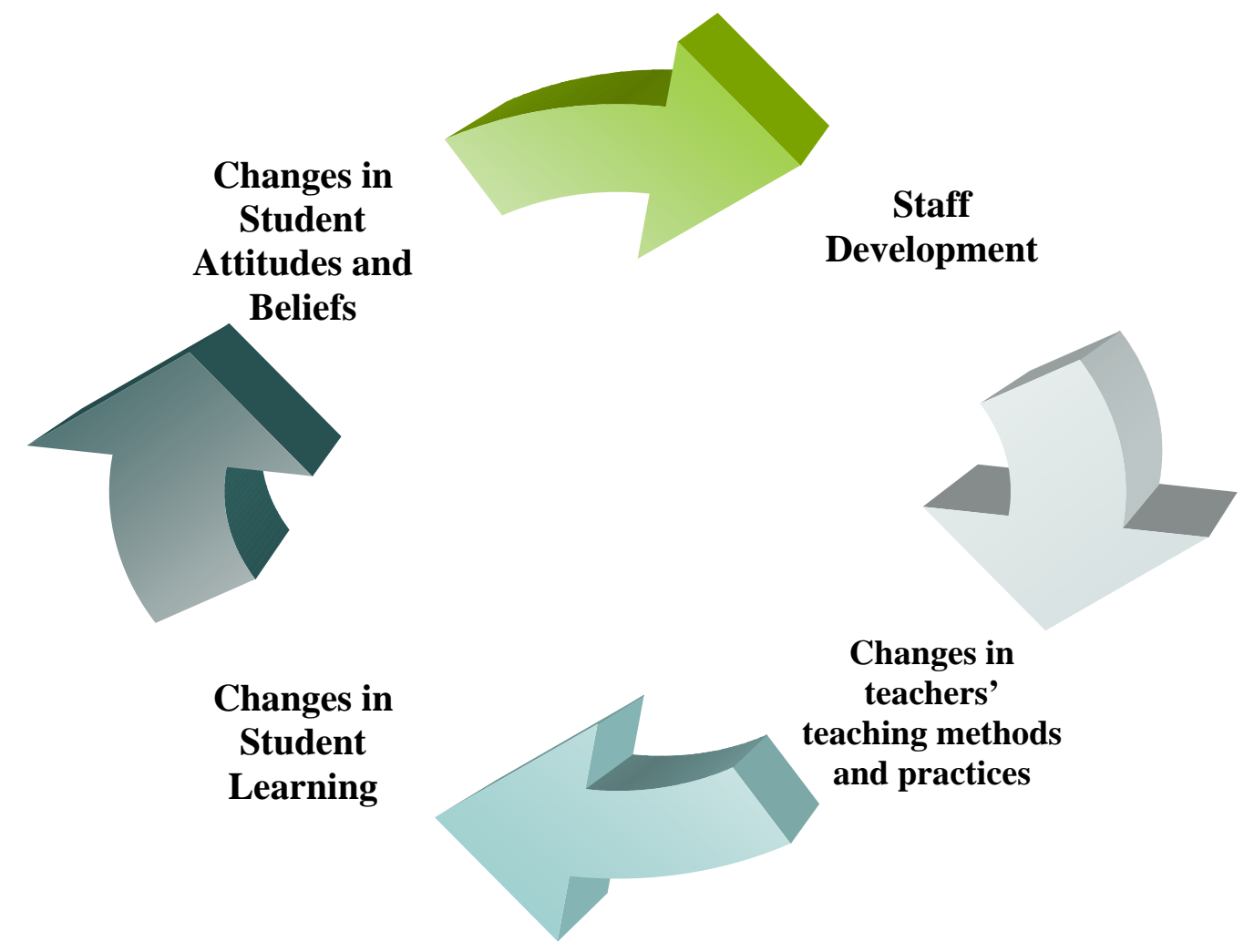

The pedagogy of physical education consists of a multifaceted relationship between physical activity and the introduction of it to the school curriculum. The relationship between physical activity and physical education still seems to be a highly debated concept. Some believe there is no place for physical activity within schools (Hui, 2001), whilst others are strong activists for integrating it into the school curriculum (Bain, 1990, in Collier \& Hebert, 2004; Hellison, 2008 in Connor, 2009).

The aim of physical education classes, according to Guedes (2007) is to instruct the human body about movement and encourage skill development amongst students so that they can become increasingly dexterous in numerous types of physical activities. Bulger, Housner \& Lee (2008), Johnson (2008) and Petrie (2008) discussed and debated various confounding and contributing factors such as the actual grading or evaluation of PE, the teaching methods employed and the effects on the students that need to be taken into consideration by the schools and everyone else involved in the wider communities in order to optimise pedagogical practices within schools. 
In the United States of America the National Association for Sport and Physical Education (NASPE) outlines the national standards and benchmarks that students need to achieve in order to pass each year's grade level of physical education (Bulger et al., 2008). According to NASPE, assessment is required for the development of teaching and learning, corroboration of principles and the documentation of students mastering specific course content (Johnson, 2008). In order to pass, the students need to know and understand the implications and rewards of being physically fit; they need to take part in physical activity on a regular basis and they need to understand the principles and significance of a physically fit and healthy lifestyle. Despite these clearly outlined standards, some schools in the USA are still failing at meeting the requirements in their PE curriculum (Chen, 2006 in Bulger et al., 2008).

One of the problems of failing to meet the requirements seems to lie with the PE teachers themselves and the ways in which they grade and evaluate what the students are learning and comprehending. McKenzie, Sallis, Faucette, Roby and Kolody, (1993) found that PE classes taught by PE specialists are more successful, in terms of quality time spent in physical activity and overall participation amongst the students, compared to classes taught by non-specialist PE teachers. This is important to take note of, as the majority of PE teachers within New Zealand primary and intermediate schools are non-specialists who may only have limited training in the pedagogy of physical education (Petrie, 2008). Henninger and Coleman (2008) described several strategies that physical educators can employ in order to maintain a safe, fun and most importantly productive environment for all physical education students. They suggested that unacceptable behavioural issues, such as non participation, lack of concentration and boisterousness, are more common in PE classes, compared to other classes and that these behavioural problems often hinder the students' performance in physical education. Some of their suggested strategies were aimed at improving PE teachers' capabilities including: getting to know the students as individuals; being able to identify which students distract one another and which students are unable to work in a group setting; maintaining reciprocated respect; having an abundance of patience and importantly having a sense of humour.

Related to the teachers' ability to manage the PE environment, is their ability to create a suitable atmosphere in order to maximise the students' learning opportunities. 
Epstein (1989, in Boyce, 2009) formulated six structural characteristics that can assist PE teachers to organise and facilitate instructional climates to benefit and optimise student participation in PE. These characteristics are identifiable by the acronym TARGET. They are: task, authority, recognition, grouping, evaluation and time. These six characteristics can be manipulated by teachers to formulate two main types of climates or working environments in PE classes: the mastery climate (which is motivationally driven) and the performance climate (which is egotistically driven), (Boyce, 2009). Teachers have the ability to manage and coordinate physical activities in order to reflect either one or both of these climates. According to Ames and Archer (1988, in Boyce, 2009) the mastery based climate appears to motivate the students more with regards to the effort they put in, their improvement in selected activities, increased levels of cooperation and persistence; decreased levels of boredom and generally a more positive attitude regarding physical education. The performance based climate in comparison, is identified by lower motivational levels; increased levels of boredom and an increase in negative attitudes towards physical education in general.

Table 1: Summarising the differences between Mastery and Performance Climates according to the TARGET Structure. (Adapted from Ames, 1992b, in Boyce, 2009)

\begin{tabular}{|c|c|c|}
\hline TARGET Structure & Mastery Climate & Performance Climate \\
\hline Tasks & $\begin{array}{c}\text { Challenging and diverse } \\
\text { types of activities }\end{array}$ & $\begin{array}{c}\text { Non-challenging, similar } \\
\text { types of activities }\end{array}$ \\
\hline Authority & Students & Teachers \\
\hline Recognition & $\begin{array}{l}\text { Based on individual } \\
\text { development, given } \\
\text { privately }\end{array}$ & $\begin{array}{c}\text { Based on social } \\
\text { comparison, provided } \\
\text { publicly }\end{array}$ \\
\hline Grouping & $\begin{array}{c}\text { Cooperative learning, } \\
\text { peer interactions }\end{array}$ & $\begin{array}{c}\text { Grouping based on skill } \\
\text { and fitness levels }\end{array}$ \\
\hline Evaluation & $\begin{array}{c}\text { Based on activity } \\
\text { mastering and general } \\
\text { improvement }\end{array}$ & $\begin{array}{c}\text { Based on winning and/or } \\
\text { outcome performance }\end{array}$ \\
\hline Time & Based on personal ability & Same for all students \\
\hline
\end{tabular}


Another important aspect regarding the pedagogy of PE is how individual schools execute the curriculum. It is common practice in New Zealand for teachers to be handed a year long plan from the Head of their Physical Education Department or someone in a similar position, (Petrie, 2008) that clearly outlines the curricular objectives for the year. Each of the individual teachers is then responsible for integrating the year plan into their scheduled PE classes. Petrie (2008) found that as a result of this widespread practice, teachers often veer off the outlined curriculum objectives. Times spent in PE classes are mostly teacher-centred and consist of a warm-up session, followed by a short period of physical activity (which includes skill teaching and/or game playing) and warming down. It is important to consider the possible effects that these pedagogical practices might have on students' levels of participation. This apparent discrepancy between schools could result in students having very different experiences of their PE classes. It could alter their perceptions and determine their attitudes and perspectives towards PE in general.

To summarize, it is now known that pedagogical practices can have far reaching effects on student participation and student perceptions regarding their PE classes. The evaluation or grading of PE participation, the climate that is created and the general disposition that $\mathrm{PE}$ teachers have are important matters related to pedagogical practices. According to Connor (2009:6), a good physical education teacher is defined as someone who can combine physiological, automatic, mental and other aspects of human movement that encourages student participation in extensive physical activities whilst upholding an entertaining environment.

\section{Other Possible Physical Education Concerns}

The literature has already touched upon possible problem areas within the teaching and general practice of physical education. Some of these problems will now be identified and discussed in further detail in order to shed some light on the complexity and intricacy of the topic at hand. 
Beyer (2008) and Petrie (2008) discussed some of the challenges that physical educators are being faced with in aligning their standards with the outlined PE curriculum. Physical educators are often faced with challenging circumstances (such as challenging student behaviours and other curriculum pressures) which directly affect their teaching styles (Henninger \& Coleman, 2008). As Stelzer (2005) and Jenkins, Jenkins, Collums and Werhonig (2006) point out it is important that the physical education classes have lasting effects and impacts on the students' lifestyles well beyond their school years because of the numerous social, psychological and general health benefits provided. The physical education curriculum content and the ways in which the curriculum content is executed therefore needs to be able to motivate students of all capabilities and ages to become and stay physically active for the remainder of their lives (Daley \& Ryan, 2000; Headley, 2001). Beyer (2008) discussed three main barriers to obtaining these goals. Firstly the amount of time and the types of activities provided by the school to practice PE might have a negative influence on the impact and quality of its execution. Secondly the levels of physical activity needs to be optimised, for example the students' heart rates need to be elevated for a specific amount of time in order to gain optimal use and value from their PE classes, especially if the focus is on physical fitness levels. The third barrier, according to Beyer (2008), is the challenge to maintain physically active lifestyles beyond the parameters of the school grounds.

Johnson (2008) focussed on the challenges that PE teachers are faced with, in regard to grading the students' performances within their PE classes. This is an important aspect of PE pedagogy. According to Darst and Pangrazi (2006, in Johnson, 2008) the ways in which students are evaluated and graded within their PE classes will ultimately shape their attitudes towards it. When a negative grading approach is employed, students often view it as a form of punishment for not performing. This could result in a number of negative emotions (including anger, lack of motivation, antipathy and even evasion), that will ultimately be associated with PE as a subject. A positive grading approach is more likely to increase student participation, incentive, self-direction and accountability (Darst \& Pangrazi, 2006, in Johnson, 2008).

Johnson (2008) found that the challenges faced by the teachers with regards to grading students' PE comprehension and performances are mostly as a result of the 
students, their parents and their surrounding (mostly uncooperative) communities. As the literature has suggested, students are often disruptive and can be even more so within their PE classes. This can make it very difficult for the teachers to evaluate and grade the students' level of participation, performance and comprehension. Johnson (2008) therefore suggests the use of an achievement based grading system which will enhance the actual learning of PE principles more effectively compared to the common documentation of learning, which focuses only on aspects such as attendance, participation and conduct. According to Johnson (2008) the achievement based grading system focuses on individual student responsibility, positive grading and student ability to master outlined objectives. The achievement based grading system is therefore more focussed on positive enhancement of both learning and teaching.

Jenkins et al., (2006) found that other aspects such as PE curricular topics, the physical educator and the social environment all contributed both positively and negatively to student perceptions of their PE courses. Students' perceptions of their PE courses are influenced by the familiarity of their physical activity (Steinhardt, 1992, in Jenkins et al., 2006). Students enjoy participating in familiar physical activities. According to Jenkins et al., (2006) several other aspects played a role in the level of enjoyment the students got out of their PE courses, including teacherstudent relationships, course content, variety/range of physical activities and the social environment of the class. Some students felt positively about the topics presented to them, whilst other students felt negatively about the same topics. This study is a clear indication that there is no one-model-fits-all, especially regarding physical education. It is always possible that some students might express interest in particular PE concepts whilst other students might demonstrate indifference towards those same concepts. Jenkins' et al., (2006) study clearly demonstrates the complex, dynamic nature of student perceptions regarding participation in physical education classes.

Stephen Virgilio (2009) emphasized the need for a more coordinated, comprehensive, all inclusive approach to physical activity, and more specifically physical education within the school domain. Virgilio focused on the need to have students, schools, parents and communities agreeing about the quality and importance of participation in physical activity. He stressed the importance of having adequate time and resources 
available in order to promote and maintain physical fitness levels, before, during and after school hours.

\section{Physical Education in New Zealand}

The increased focus on rising obesity levels within New Zealand has lead to an overview of what is being taught and more importantly what is being learned across the curriculum. Schools have been seen as both the problem and the solution to the dilemma. More specifically, the qualities (or lack thereof) of physical education within schools have been under scrutiny (Kirk, Macdonald \& O' Sullivan, 2006). As a result there has been an abundance of focus on forecasting, observation and evaluation of the subject area with the consequent modifications in the teaching and evaluation of PE in the New Zealand syllabus. One of these was concerned with an increased emphasis on the social and socio-cultural aspects of PE (Wright, Macdonald, \& Burrows, 2004). A socio-cultural perspective now underpins most PE syllables both in Australia and in New Zealand, especially since the union between health education and physical education (HPE).

In light of this, Culpan (2008) found that the Ministry of Education's 1999 release of the Health and Physical Education in New Zealand Curriculum (NZHPE) initially led to some curricular changes being made, but as time progressed many schools and teachers reverted to their old familiar PE practices. The New Zealand Curriculum (NZC) was released in 2007. The impacts of NZC, which included small changes to the NZHPE, have not yet progressed as it was intended. Culpan (2008) criticised the NZC suggesting it does not improve and/or extend physical education, more than the NZHPE aimed to do.

In addition, Macdonald (2004) suggests that it is unlikely that PE teachers will adopt a completely new curriculum. They are more likely to try it out for a while, before returning to their old practices and familiar methods of teaching. She argued that the implementation and introduction of new curriculum practices have had very little effect on students because of teachers' refusal or inability to adapt and adhere to a 
new curriculum. This could be due to the fact that many of the curricular suggestions fall short of the students' and teachers' needs. In Macdonald's (2004) opinion the current curriculum is based on a modernist perspective within a postmodernist milieu. The curriculum limits the sovereignty and liberty of our teachers and their students as it does not take individual differences (socioeconomic status, sex, body shape and ethnic backgrounds) into consideration. The curriculum also failed to take into account that students living in today's society have changed. The students themselves have become consumers of corporate capital and technologies; therefore the ways in which the students interact with their curriculum have also changed. Macdonald (2004) argued that students of today see their curriculum as a product of their circumstances and often opt out of participation. She concluded that curriculum structures need to employ a postmodernist perspective that is more client-focussed, in order to become a pertinent, significant phenomenon within New Zealand schools.

The importance of a well structured PE curriculum was stressed by Clive Pope (2007). He argued that it is time that students start to "play seriously". He wanted to emphasise New Zealand nationalism through participation in sport, in particular children's participation in physical education. He described the current curriculum as dynamic, an ongoing discussion between educators, scholars, policy developers, researchers and resource suppliers. In contrast to Macdonald's (2004) findings, Pope describes the New Zealand PE curriculum as being all inclusive in the sense that a general consensus has been reached about its design and implementation. Macdonald (2004) argues that the current curriculum excludes students as it does not consider the ways in which they have been shaped by cultural, societal and even political aspects. Macdonald feels that the curriculum is out of touch with students and that even if new changes were made, teachers will be more likely to revert back to old pedagogical practices. Pope (2007) highlighted that PE could and should be seen as a contrivance to promote and educate people about New Zealand's sport culture in a more general sense. He did not feel that the current physical education curriculum put an emphasis on sport, sport participation and/or sport performance. Pope did agree with Macdonald (2004) that the current curriculum is restrictive as it does not enable students to learn and progress as well as they should be able to. However, Pope's focus was on the participation in sport in a more socio-cultural sense and how PE can be used as a tool to promote sport participation. Macdonald (2004) was more 
concerned with the educational value that students are receiving from their PE curriculum. She believes that students should be viewed as customers and that their perceptions should be utilized to enhance and promote the delivery of higher quality physical education within New Zealand.

Pope's (2007) research is also in contrast to Boyce's (2009) research as it suggests that a performance based climate (which is mostly sports driven) is what is required in New Zealand schools. Boyce strongly refutes that such a climate will promote active participation in PE. She argues the need for a more individually based and focused climate where students are not required to compete against each other. According to Culpan (2008), it is necessary to reorganize and restructure these communal focuses on the important aspects of health and the participation in physical activity.

Petrie (2008) found that the practice and teaching of physical education within New Zealand schools differ from school to school. Although there is some overlap between some of the PE practices, the majority of the physical education programmes differ in context and the ways in which they are presented to students. The teachers that participated in her research declared that they did not always present PE on a regular basis due to confounding and extraneous factors such as weather and/or other school commitments. PE was viewed as time-out for the students and teachers but only when all other academic work was on schedule. Petrie (2008) outlined several factors that influence and affect PE in New Zealand schools including school goals that are focused on other priority areas, lack of physical space and resources, and teachers' judgments about what they think PE should include. The findings of this study suggested that the ongoing development and improvement of PE is viewed as being a minor priority within New Zealand schools.

Some of these curriculum based (defining PE and its grading systems) and pedagogy (teaching methods employed) related problems as outlined by Beyer (2008), Bulger et al., (2008), and Johnson (2008) are evident within the New Zealand physical education curriculum. Assessing student levels of learning via the grading system and/or teacher evaluation methods is problematic in New Zealand as it is not consistent across the board. In addition, the allocated time for physical education seems to be on the decline (Hardman \& Marshall 2000, in Hamlin \& Ross; Ministry 
of Health, 2003 also in Hamlin \& Ross, 2005; Beyer, 2005; \& Petrie, 2008). Such issues are preventing students in New Zealand schools to enjoy and benefit from participation in good quality PE classes.

\section{Quantity of Physical Education}

There is concern expressed (Hardman \& Marshall 2000, in Hamlin \& Ross; Ministry of Health, 2003 also in Hamlin \& Ross, 2005; Beyer, 2005; \& Petrie, 2008) that the amount of time set out for physical education within the school setting is in decline. An important question arises. How much physical activity is required in overall schools' PE classes to acquire the recommended levels of physical activity and overall physical wellness? Who decides what these recommended levels will be?

According to Siegel (2008) several policy groups identified that PE classes should be viewed as an indispensable way for children to meet their daily physical activity levels. In spite of this, very little is known about the actual amount of physical activity that students participate in during their PE classes. He found that lesson length for PE classes is on average, approximately 33 minutes, of which only 18 minutes in total were spent in active participation of physical activity. Siegel (2008) strongly recommended increasing the amount of physical education presented at schools. Similarly McKenzie et al., (1993) and Petrie (2008) also found that the amount of PE in schools, internationally, needs to be increased in order for students to benefit from it. The amount of quality time that students get to spend in PE is often hampered by deficient curricular choices made by the teachers. These choices are directly related to increased levels of inactivity within the PE classes (Faucette, McKenzie \& Patterson, 1990 in McKenzie et al., 1993). Hill and Hannon (2008) also concluded that the rostered times for PE influences student choices with regards to the types of activities they might engage in.

Another aspect to consider is that the wider the range of possible physical activities, the more interested the students will be, which in turn will increase the actual amount of quality time they spend being physically active within their PE classes. Hill and 
Hannon's (2008) research findings are consistent with those from other studies (Bradley, McMurray, Harrell \& Deng, 2000 in Hill \& Hannon, 2008; \& Hill \& Cleven, 2005 also in Hill \& Hannon, 2008) which highlighted that swimming, bowling and certain types of ball games are favoured by the students These types of activities might have been selected by the students due to their familiarity and/or the availability of its equipment and other resources. Nanci Hellmich (2006) warned that the simple increase of time to allocated PE classes will not necessarily get the students to be more active. Instead the implementation of student choice, alongside adequate and appropriate methods of facilitation by the teachers could lead to increased levels of student participation within their PE classes.

\section{Choice Based Physical Education Programmes}

The concept of choice based physical education programmes was first considered in the 1950s (Shimon, 2007) yet it appears to have been adopted only by a few educational institutions. Some authors argue the importance of providing students with a choice based physical education programme (Chambers, 1991; Headley, 2001; Pagnano \& Griffin, 2001; Blakemore, 2003; \& Hill \& Hannon, 2008), as beneficial to everyone involved, including the teachers and the students. Hill and Hannon (2008) stated that a choice based PE programme cultivates collective conscientiousness and endorses personal decision making by giving the students a perception of ownership over their PE curriculum. The authors warn that a choice based programme should not be seen by the students or the teachers as taking a break from other subjects. A choice based programme's success is highly dependent on the notion of intent, and should have clearly outlined goals and objectives in place. Expectations, restrictions and a level of respect need to be present at all times when this type of programme is being employed.

This type of programme places the students at the core of the learning process. According to Lambert (1996, in Pagnano \& Griffin, 2001) students learn best when they are actively engaged, compared to when they receive information submissively. Students learn at different rates and a choice based programme accommodates this. 
Smith (2005) argued that it is because of student differences and the benefits it could have for individual students that a choice based programme should be implemented within the PE curriculum. He stated that the curriculum usually accommodates those students who have physical difficulties but it seldom accommodates those students that are physically gifted. A choice based programme provides space and opportunity for gifted students to push their physical boundaries even further, whilst still falling within the domains of the outlined curriculum. The choice based programme allows for the adjustment of individual differences, preferences and uniqueness. Pagnano and Griffin (2001) and Smith (2005), both emphasized that a choice based programme puts the students in a position of authority, and as a result it boosts the students' comfort and confidence levels. The implementation of a choice based programme does not just concern the choice of the type of physical activity the students can participate in. It can also concern the choice of partners, equipment and time that is available to them. Thompson and Wankel (1980: in Condon \& Collier, 2002) found that students are more likely to tolerate an activity of their choice, compared to an activity that they had no choice in.

A possible problem with regards to the implementation of a choice based PE programme is that it needs to consider what type of activities the students would like to include into the curriculum. Hill and Hannon (2008) focused on the identification of the recommended categories of activities and possible different choices based on gender differences, skill competency differences and participation differences of students. Their study, along with several other studies (Hill \& Cleven, 2005 in Hill \& Hannon, 2008; \& Sallis, Prochaska \& Taylor, 2000 in Hill \& Hannon, 2008) found that there are a number of aspects that could manipulate the students' choice of certain physical activities. These include community and environmental influences (such as: socio-economic status, living area and cultural influences), sex (boys prefer more physically strenuous types of activities compared to girls), age (decline in participation is evident as students gets older), the students' levels of skill and extra curricular sports participation.

Allowing choice based curricular activities could only augment student participation in physical activity. If the students feel they do have a choice they are more likely to learn and remain engaged when the chosen activity holds significant and important 
benefits for them. The effect of choice on motivation is evident also in Condon and Collier's (2002) and Johnson's (2005) study where adolescent girls' levels of motivation were tested with regards to the level of their participation in physical activity. The control group of girls had no choice of activity, whilst the second group of girls could choose their own type of physical activity. The findings suggested that the girls who were able to choose the types of activities were more motivated compared to the control group. These findings are consistent with other research (Pagnano \& Griffin, 2001; Condon \& Collier, 2002; \& Smith, 2005) which argues that adolescent students perform better in an environment where they have a higher sense of independence and choice.

\section{Relationship between Physical Fitness and Academic Performance}

In addition to the quantity of $\mathrm{PE}$ and choice based PE programmes, a third component of physical education to consider is the influence, effects and relationship between physical fitness and academic performance. There is debate around whether physical fitness levels and academic performance is positively correlated. While there is scientifically based research in support of this correlation (Chambers, 1991; Castelli et al., 2007; Grierson, 2005; \& Chomitz, Slining, McGowan, Mitchell, Dawson \& Hacker, 2009) there are also a number of authors who do not support the existence of such a correlation (Sallis, McKenzie, Kolody, Lewis, Marshall \& Rosengard, 1999 \& Yu, Chan, Cheng, Sung \& Hau, 2006).

Bailey (2006), an advocate for promoting good quality physical education classes within schools, aimed to gather sufficient scientific evidence to prove that physical education and/or sport within the school setting is advantageous in several areas of children's lives. Five specific domains were identified and the effects of exercise through the school curriculum are discussed in relation to each domain. The five domains are physical, lifestyle, affective, social and cognitive. Bailey (2006) asserted that when physical education is presented in an age and ability appropriate way it 
could aid in the development of academic and cognitive development. He highlighted the importance of understanding that it might not just be the activity itself that promotes academic achievement. Students' academic performance levels might be related to the specific nature of interactions that the student associates with the activity, for example the relationship with the coaches/trainers/PE teachers and fellow students. Some of these interactions might lead to improved self-confidence and/or self-esteem, which in turn might lead to better school grades. Bailey (2006) argued that there might not be a direct causal relationship between physical exercise and school performance, rather participation in good quality physical education classes might have a positive 'knock-on' effect on the improvement of the students' academic performances.

Bailey concluded from other research findings (Fejgin, 1994, in Bailey, 2006; Talbot, 2001 in Bailey, 2006; \& Lau, Yu, Lee, So \& Sung, 2004, in Bailey, 2006) that physical exercise can potentially improve academic functioning because it has been scientifically demonstrated to enhance blood flow to the central nervous system, decrease stress by improving mood, increase mental alertness and improve selfesteem, which are all factors shown to have a positive influence on children's school grades. It is not possible to conclude that there is a one directional, causal correlation between participation in physical activity and increased academic performance. What Bailey is suggesting, is that there might be a myriad of confounding issues that are contributing to the increased levels of academic performance in the presence of physical activity, but he emphasised that the evidence for this is varied and more research is required in this field.

Sallis et al., (1999) and Blakemore (2003) focussed more on evidence that increased time spent in PE classes will not negatively effect the school children's academic achievement. Their objective was to find out whether a specific program namely the Sports, Play and Active Recreation for Kids (SPARK) programme is effective. SPARK is an all-inclusive and professionally designed development curriculum that aims at promoting physical education classes within the school curriculum and also aims at increasing the children's awareness of the benefits of participating in physical activities outside of the school setting. These authors examined whether physical education, or more generally the notion that physically fit and healthy students could 
achieve better grades at school compared to those children who lacked physical exercise. Other issues with regards to children's academic grades were raised and discussed including parents' education levels, family involvement in the child's academic achievement, the socio-economic district in which the child lives and which subject areas might benefit more from being physically active. The researchers (Sallis et al., 1999; \& Blakemore, 2003) distinguished between the three main subjects of reading, mathematics and language and some of their research findings suggested that student participation in increased, quality physical education classes administered by SPARK trained teachers could potentially lead to positive effects on achievements in these three areas.

From a positivistic biological standpoint, Blakemore (2003) emphasised the importance of having good quality PE classes entrenched within the school curriculum, while Castelli et al., (2007) looked at the relationship between physical fitness levels, according to Body Mass Indexes $\{$ BMIs $\}$, and academic performance. These studies emphasized rising concern with regards to obesity levels being on the increase amongst children and their apparent lack of interest in physical activity. They also looked at how a child's weight might affect their academic performance. The authors argued that there is a positive relationship between academic achievement and physical fitness and a negative correlation between a child's weight and their academic performance. These authors emphasised the need to promote fitness amongst children. Since physical education is the only form of exercise for a rather large group of students, the researchers are endeavouring to encourage, promote and raise awareness of the importance of leading physically active lifestyles. Their aim is to get this message across to school administrators and policy makers in order to prevent further reductions in funding for regular, good quality physical education.

Headley (2001) investigated the extent to which physical exercise contributes to overall wellness of adolescents, not just their academic performance. The findings of her study suggested that higher levels of physical exercise for children lead to improved relationships with their parents, decreased levels of depression, more participation in a variety of different sports, less likelihood of using drugs and increased school grades. Headley (2001) found that an overall healthy child is more 
likely to be more contented in various other areas of their life. She also highlighted the importance of having enough positive role models for adolescents and the importance that adolescents themselves realize just how beneficial physical wellbeing can be for them.

A number of authors (for example: Daley \& Ryan, 2000; Blakemore, 2003; Tremarche, Robinson \& Graham, 2007; \& Stevens, Yen, Stevenson \& Lochbaum, 2008) have focussed on the apparent link between physical health and mathematics. Some findings suggested that mathematics is a subject where students could possibly benefit more from being physically fit compared to other subject areas. Chomitz et al., (2009) found that there is a definite correlation between physical fitness levels and mathematic test scores, but they were unable to determine the direction of this causal relationship. This correlation between mathematics and physical fitness levels was found to be stronger than that between English test scores and physical fitness levels. The literature is not yet able to fully explain the correlation between physical fitness and mathematics, but there are several possible reasons. Possible explanations include that students who express this causal phenomenon might be more achievement oriented across all subject areas compared to other students. A second possible explanation is that high physical fitness levels might contribute to better overall health, which in turn could account for improved academic performance and as physical fitness is known to augment concentration levels (Lambert, 1996, in Pagnano \& Griffin, 2001; \& Headley, 2001) this could in turn have positive effects on mathematic scores. Another possible explanation is that physical fitness levels improve mental health (including cognitive functioning) and self esteem which is known to positively affect academic performance.

Nilges and Usnick (2000) suggested that mathematics and physical education should be combined into an interdisciplinary curricular system. They argued that PE and mathematics share a focus on spatial awareness and development and that it is due to these similarities that the subject areas should move from an integrated to an interdisciplinary curriculum. They argued that the correlation between physical fitness levels and mathematics is due to the fact that students who have robustly developed spatial abilities are more primed to learn about geometric dimensions and number theories in general. Although these authors have made some ground breaking 
discoveries on the link between physical fitness levels and achievement in mathematics, a lot more research is needed in order to fully comprehend this phenomenon.

In conclusion, some of the suggested outcomes (Headley, 2001; \& Bailey, 2006) from doing physical education include improved health, more highly developed social skills (and interpersonal relationships), an increase in self-esteem and potential improvement in academic performance.

\section{Range of Physical Activities}

There is substantial evidence from the literature (Nixon \& Cozens, 1952; \& Petrie, 2008) to support the view that physical education is particularly complex and dynamic in its disposition. Students' perceptions are easily influenced by the characteristics of their PE classes, including the amount of time they spent being physically active, the level of choice they have regarding aspects of the classes, the pedagogical practices and the class environments. Other related factors include age appropriateness, gender differences and actual pedagogy of PE. All these aspects need careful consideration when designing, constructing, facilitating and executing the curriculum.

Further, PE activities have remained mostly unchanged, globally, for over half a century (Shimon, 2007). While there are many countries where schools have adapted and improved physical education programmes Shimon (2007) felt it was important to bring to attention that physical education standards in a large number of schools are still considered unacceptable, 'one size does not fit all'. The type of activities outlined in the curriculum will not satisfy and motivate all students. The importance and benefits of having a choice from a wide variety of physical education activities seems to be the obvious approach. However, according to Hardman and Marshall (2000, in Hamlin \& Ross, 2005) a steady decline has been evident within schools with regards to the range of physical activities that are available to students within their PE classes. 
Petrie's (2008) study elucidated a number of actual physical activities that are available to New Zealand students. They include participation in aquatics, small ball games (including cricket and softball), large ball games (such as netball and basketball), gymnastics, athletics (including cross country), dance and fitness (jumping, skipping and/or running). The range might seem extensive, but these types of activities are not always available to all the students across New Zealand and some schools might only practice some of these activities, not the entire range.

Smith (2004) highlighted the importance of having a range of physical activities for the students to choose from. Her study, along with other studies (Ryan, Fleming \& Maina, 2003 in Smith, 2004) found that having a variety of physical activities within the PE curriculum increased students' positive perceptions about their PE classes. Jenkins et al., (2006) and Hill and Hannon (2008) emphasized that physical education is more likely to thrive within the overall school curriculum if it includes activities that are attractive to students. It is very important to also take the gender differences with regards to activity selection into account as gender differences and gender preferences can have major effects on the students' perceptions and attitudes towards their PE classes (Luke \& Sinclair, 1991, in Hill \& Hannon, 2008).

\section{Ethnic and Gender Differences, in Participation in Physical Activity}

As outlined previously there is a nationwide concern about the rising obesity levels amongst children, this concern is not only contained within New Zealand, but seems to be a global dilemma. Particularly alarming, according to Hamlin and Ross (2005) is the considerable deterioration in physical activity amongst Māori children. According to Sport and Recreation New Zealand (2003d in Hamlin \& Ross, 2005) there has been a noticeable decrease from 1997 to 2001, with Māori children showing an increasing lack of interest in participating in physically active leisure activities. 
Hamlin and Ross (2005) also highlighted that individuals of lower socioeconomic statuses (SES) are less likely to be physically active and in New Zealand this group is over-representative of Māori and Pacific peoples. Therefore these ethnic groups are mostly affected by sedentary lifestyles. For example, children growing up in families with low socioeconomic backgrounds are more likely to live in dangerous locations, where the crime rates are higher in comparison to other areas within New Zealand and they are more likely to live in areas that are without the benefit of parks and playgrounds for safe outdoor play (Evans \& Kanttowitz, 2002, in Stevens et al., 2008). Children living in higher SES areas have more access to outdoor play and official participation in team and individual sports.

This is a problem for which there is no quick fix. There will always be children that live in less privileged areas compared to others. It is important to identify these areas to implement and promote physical activities amongst the families living there. A 2001 SPARC study (Ministry of Health, 2003 in Hamlin \& Ross, 2005) identified the Counties-Manukau region in New Zealand as having the lowest levels of physically active five to 17 year olds. Pacific girls and girls identified as belonging to "other" ethnic groups were found to be the least active. There is an identified gap in the research focussing on the investigation and prevention of a further decline in participation in physical activity amongst New Zealand's indigenous peoples (Shilton \& Brown 2004, in Hamlin \& Ross, 2005). Although there is an existing nationwide program aimed at increasing active leisure participation amongst Māori called $\mathrm{He}$ Oranga Poutama (Sport and Recreation New Zealand, 2003a, in Hamlin \& Ross, 2005) more needs to be done to promote healthier, more active lifestyles amongst these at-risk groups.

The news is not all bad though, according to West, Reeder, Milne and Poulton (2002, in Hamlin \& Ross, 2005) New Zealand youth were reported to take part in a wider range of physical activities and participated in physical exercises more frequently compared to Scottish youth. This could be due to the exposure to a wider range of cultures and ethnicities within New Zealand, possibly leading to the introduction of different types of physical activities to New Zealand youth. Another possible reason why could be as a result of the weather and the geographical layout of New Zealand which allows for both winter, (for example mountaineering, skiing and snowboarding) 
and summer activities (for example water sports including swimming, rowing and water polo).

Clarken (1995, in Davis 2003) found that there has been a concern, throughout history, for the harmful effects of exercise on the female body and emotions. There has been a misconception that women will somehow be harmed by having an education and that they will be particularly harmed by participating in physical activity. This misconception held back female involvement in all types of physical activities until approximately 1900, when certain types of sports and physical activities were considered acceptable for women to participate in (Hutchinson, 1995, in Davis, 2003). Due to these historical effects of cultural conditioning, some scholars (Satina, Solmon, Cothran, Loftus \& Stockin-Davidson, 1998, in Davis, 2003; Sprague \& Edstrom, 2000, in Davis, 2003) have argued that females have an inherent weakness (inability or incapacity) in comparison with males, in participating in physical education and activity.

Girls and boys of early adolescent (10 to 13 years) age exhibit different types of behaviours when it comes to engaging in physical activities. Boys of this age are more likely to engage in more physical leisure time types of activities, for example playing sports, cycling and being generally more inquisitive whereas girls are more likely to spend their leisure time in a sedentary manner, focussing more on socializing in small groups (Davis, 2003). These differences between male and female behaviour results in boys being more likely to reach the recommended level of 30 to 60 minutes a day of moderate intensity physical activity compared to their female counterparts. This lower level of physical activity means that boys were found to have elevated heart rate levels more frequently compared to adolescent girls of the same age (Sport and Recreation New Zealand, 2003a, in Hamlin \& Ross, 2005).

This seems to be a common finding across the world, as Armstrong and Van Mechelem (1998, in Hamlin \& Ross, 2005) and Pate, Long and Heath (1994, in Hamlin \& Ross, 2005) also indicated that young adolescent girls seem to be less physically active compared to boys of a similar age. Hutchinson (1995, in Davis, 2003) stated that in order to ensure gender equality in PE classes, it is the teachers' 
responsibility to produce a setting in which both sexes feel safe to explore and develop their full capacities in physical activity.

David and Myra Sadker (1994, in Davis, 2003) conducted a two decade long study from the 1960s through to the 1980s to investigate the behaviours teachers exhibited towards students from different genders. They found that PE classes were the second most gender prejudiced subject, second only to mathematics. The prejudiced behaviour mostly consisted of biased comments, where boys were praised more than girls, where boys were encouraged more than girls, or where these biases were reflected in how the students were addressed for example men versus girls, or the word order used by the teachers was seen as biased for example where the teachers always addressed the class as boys and girls, rather than girls and boys. BarrAnderson, Neumark-Sztainer, Schmitz, Ward, Conway, Pratt, Baggett, Lytle and Pate (2008) also noted the possible negative effects gender biased PE teaching can have on adolescent female students. They argued that teachers' support for girls' physical competence in the physical education class, contributed significantly more to their enjoyment and value of the class.

The types of activities presented in physical education might also be viewed as prejudiced. Hill and Hannon (2008) found that gender is a major determinant in the types of activities students might choose and/or participate in. Bradley et al., (2000, in Hill \& Hannon, 2008) reported that pre-adolescent and adolescent female students prefer physical activities that are not competitive or contact based in nature. Some of these types of activities include swimming, dance, aerobics and gymnastics. In contrast, boys of a similar age tend to choose types of physical activities that are team focused, competitive and more traditional, which included weight training, hockey and football. Similarly Davis (2003), Hill and Hannon (2008) pointed out that females prefer more social types of activities and males prefer more aggressive and competitive types of activities. 


\section{Fear of Fatness}

Studies conducted with young girls and their perceptions of body image, (Shewfelt, 1991; French, Perry, Leon, \& Jayne, 1996; Cherry, 1996; \& Gilbert, 1999) have drawn the conclusion that some young girls live in fear of being fat and these girls often participate in risky types of behaviours in order to prevent themselves from ever becoming fat. They see physical fitness not as a prerequisite to a healthy lifestyle but rather as a tool they can manipulate and manage to maintain their weight. Some girls find obesity more repulsive and disturbing than being physically disabled (Greenberg, 1989). Griffin, Younger, and Flynn (2004) found that this irrational fear of being overweight amongst pre-adolescent girls appears to be a worldwide phenomenon. Their study reinforced Gerrone's (2000) conclusion that pre-adolescent girls are actively trying to lose weight and their number one reasoning for wanting to lose weight is their fear of being fat, rather than an aspiration to be thin.

Similarly Greey (2000) found that pre-adolescent girls were mostly shocked and traumatized at their unexpected weight gain upon commencing their menstrual cycles and societal pressures put upon them inculcate a fear of becoming fat. A large number of girls were found to be experimenting with diverse methods of weight loss, which included active dieting regardless of body shape and size, food restriction, initiation of smoking behaviours and even self-induced vomiting. Greey (2000) highlighted that children are receiving messages that proclaim that fitness should be seen as a weight loss tool, which she argued is a dangerous message. Fitness should not be seen as a tool of weight management, but rather as a positive, fun invoking necessity for a healthy lifestyle. It is evident that young girls especially are very susceptible to pressures from their peers and from society in general.

Having reviewed factors around physical education that related to the objectives of my research, the next chapter will focus on the philosophies, epistemology, theoretical perspective, methodology and method employed when the research was conducted. 


\section{CHAPTER 3: RESEARCH METHODOLOGY}

\section{Philosophy, Epistemology and Theoretical Perspective}

The field of physical education has been the focus of many philosophical thinkers, including Plato, Jean Jaques Rosseau and Descartes to name only a few. According to Paterson and Hallberg (1965: 99) Plato had a very idealistic judgement about Juvenal's mens sana in corpore sano (a sound mind in a sound body). Plato believed that it is a sound mind that will ultimately lead to a sound body. He was not particularly interested in the preservation of the body, but he felt that the neglect thereof would ultimately lead to a distraction of the cultivation of the mind, which to him was unacceptable. Platonic views were firmly embedded in the mind or spirit. In contrast, Jean Jacques Rousseau (himself a product of the Enlightenment) was on the opposing end of the continuum compared to Plato. Rousseau valued above else, the human body and nature (Paterson \& Hallberg, 1965). Preserving the human body to re-unite it with nature was the ultimate objective for Jean Jacques. Descartes found a middle ground between Plato's philosophies and Jean Jacques Rousseau's beliefs. Descartes suggested the dual world of mind and body. He contributed to both philosophical idealism (Plato) and philosophical realism (Jan Jacques Rousseau) (Paterson \& Hallberg, 1965). For the purposes of this dissertation I will employ Descartes' philosophy, as I value both the body and the mind and I personally believe that the health and wellbeing of one will ultimately complement the other.

In preparation for this research several alternative methodological options were explored. The philosophical, epistemological and theoretical perspectives had to be applied to the topic of interest in such a way that could maximise the likelihood of accomplishing the research aims and objectives. Davidson and Tolich (1999: 25) described epistemology as one of the main concepts of philosophical thinking that can robustly be described as: "how we know what we know". Therefore, it can be said that one's epistemological viewpoint favours aspects such as rational thought; knowledge through our senses and causal relationships. The theoretical assumptions 
underlying our epistemologies effectively determine the direction of the research project, and whether a quantitative or qualitative framework is more appropriate. Kirk et al., (2006) discussed some of the problems researchers are faced with when considering their personal epistemological backgrounds and theoretical standpoints. As with Davidson and Tolich (1999), Kirk et al., (2006) warned against the careless and sometimes haphazard use of these terms. Theoretical perspectives as defined by Macdonald et al., (2002; in Kirk et al., 2006) are concerned with a humanistic approach, employed to broadly inform the research processes being utilized. According to Kirk et al., (2006) physical education research is underpinned by five different (sometimes interchangeable) theoretical perspectives. These are behavioural, interpretive, critical, post-modernist and feminist respectively. Together these different types of theoretical underpinnings offer new ways to deliberate on power structures along with the subjectivities of teachers and students within PE.

Initially these concepts were somewhat challenging. I found that my personal epistemological point of view and theoretical perspective did not best suit the design of the research project and would not meet the research aim and objectives that I had in mind. I therefore, had to find a more cohesive and strategically laid out epistemology and theoretical standpoint in order to best serve the purpose of this dissertation.

My research is quantitative and deductive in its design. A deductive methodology is where the researcher transfers from the broad spectrum theoretical opinions to specific explanations and observations, by generating hypotheses or objectives (Davidson \& Tolich, 1999). Babbie (1992, in Davidson \& Tolich, 1999) stated that deductive research is dependant on counting, calculating and measuring, which is why it is often the research framework favoured by scientists and mathematicians. It is constructed on the formal testing of existing theories about a certain phenomenon. In Figure 1, the processes involved with distinguishing between a deductive and inductive research design is presented. The structure of the research is dependant on where the research process commences. If one begins with theory formulation, the research design will be deductive in its composition; alternatively if the research is founded on observations, it will be inductive in its formation. 
Figure 2: Differentiating between Inductive and Deductive Research Frameworks (in Davidson \& Tolich, 1999: 18)
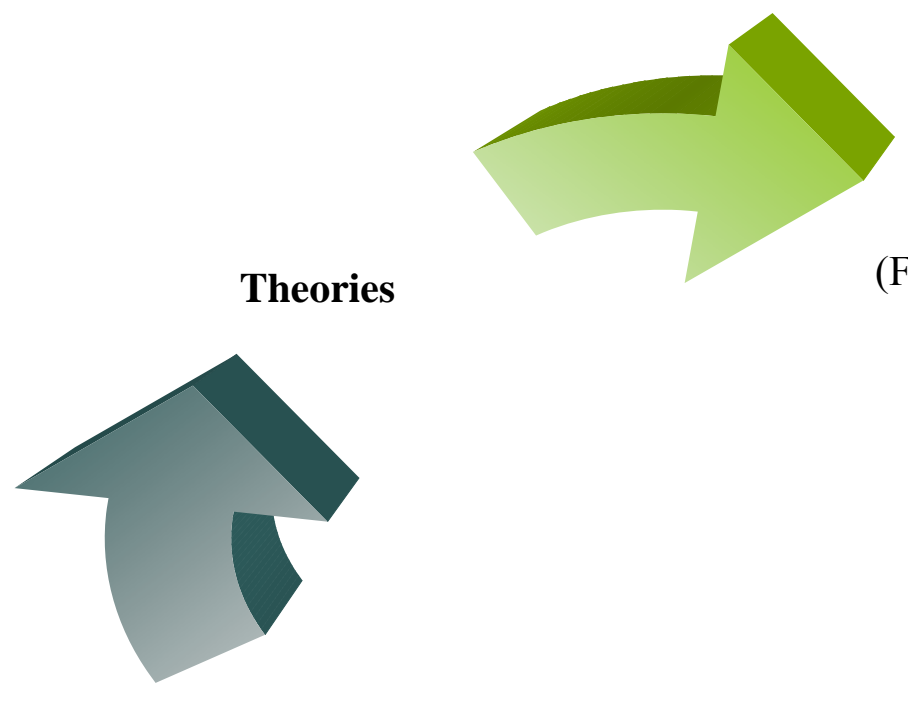

\section{Deduction}

(Formulation of

hypotheses/

objectives)

\section{Induction \\ (Empirical generalisations)}

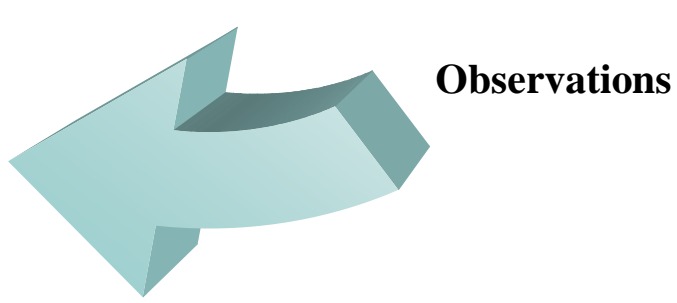

My research aims to describe, in detail, a certain phenomenon, namely the students' perceptions and experiences about the PE classes at their particular school. As Davidson and Tolich (1999: 15) put it "Descriptive research is about defining and differentiating the object of our study". A deductive research framework is also applied as it is designed with a practical outcome in mind. The output-oriented design of my research, aims at empowering the students of the chosen intermediate school. It provides an opportunity for the students to voice their acuities and experiences about their PE classes. A possible, practical implication of this could be a review of the physical education curriculum at their school and could possibly even lead to some changes, made by the teachers, in the design, scheme and pedagogical practices of their PE classes.

The research is therefore underpinned by an objectivist epistemology (Crotty, 1998) as it best serves the outlined research aim and the objectives. An objectivist epistemology argues that objects exist as significant units which are completely independent of one's consciousness and experiences. This means that through 
sensory perceptions and a process of reasoning, people are able to achieve an absolute knowledge of their respective environments and surroundings.

Things have meaning or meaningful realities even if they exist independently from our awareness or consciousness. I therefore believe that there is pre-existing, (albeit unconscious) knowledge or preconceived perceptions amongst the students with regards to their PE classes. The objectivist epistemology argues that these things have truth residing in them as objects and that this so called "truth" can be discovered through scientifically based research (Crotty. 1998). A commonly used example, (cited by Crotty, 1998) in order to explain objectivism is that a tree in the forest is a tree, even though no one might be conscious or aware of that specific tree's existence. Objectivism implies the acceptance and worth of the phenomena we are studying and if we go about our research in the correct way we might be able to discover what is called the objective truth of that particular phenomenon (Crotty, 1998: 8).

The chosen theoretical perspective therefore is one that is in support of an objectivist epistemology. Crotty (1998: 8) describes the positivist theoretical perspective as a specific type of approach that researchers employ to make sense of their surroundings, as it is dependent on the accumulation of knowledge. Positivism discovers realities, it emphasises objectivity and it privileges rationality and empirically verifiable truths. Positivism is a western perspective that is composed of interconnected variables, meanings and prepositions that presents a methodical view of a particular phenomenon (Crotty, 1998). It employs a rational, deductive system of interrelated definitions, truisms and regulations (Davidson \& Tolich, 1999). The ultimate aim of positivistic research is to discover natural laws in order to predict and control certain events. Positivism fits my dissertation as it will take into account the majority of interrelated variables (such as the social and cultural implications that student perceptions are based upon), their meanings and prepositions in light of physical education at the specific school. 


\section{Chosen Methodology and Method}

Once the epistemological worldview and its underlying theoretical assumption are in place, there is a need to consider and formulate the underlying methodologies and methods. To fit the existing research agenda, I decided to employ a survey based research methodology. Cozby (2004) highlighted several advantages when utilising survey based research. According to him, survey based research allows the researcher to gather a large number of responses in a very short period of time. It will therefore provide an opportunity to collect a lot of information from a large number of people relatively quickly. Survey based research is also one of the least expensive options as it can accommodate resource limitations and time constraints. Information gathered by surveys allows for generalisations to be made to get a clear view of the students' general opinions and experiences of their PE classes. Figure 2 demonstrates the procedures involved when formulating a research design.

Figure 3: Diagrammatic Presentation of the Research Framework employed (based on Crotty, 1998: 4)

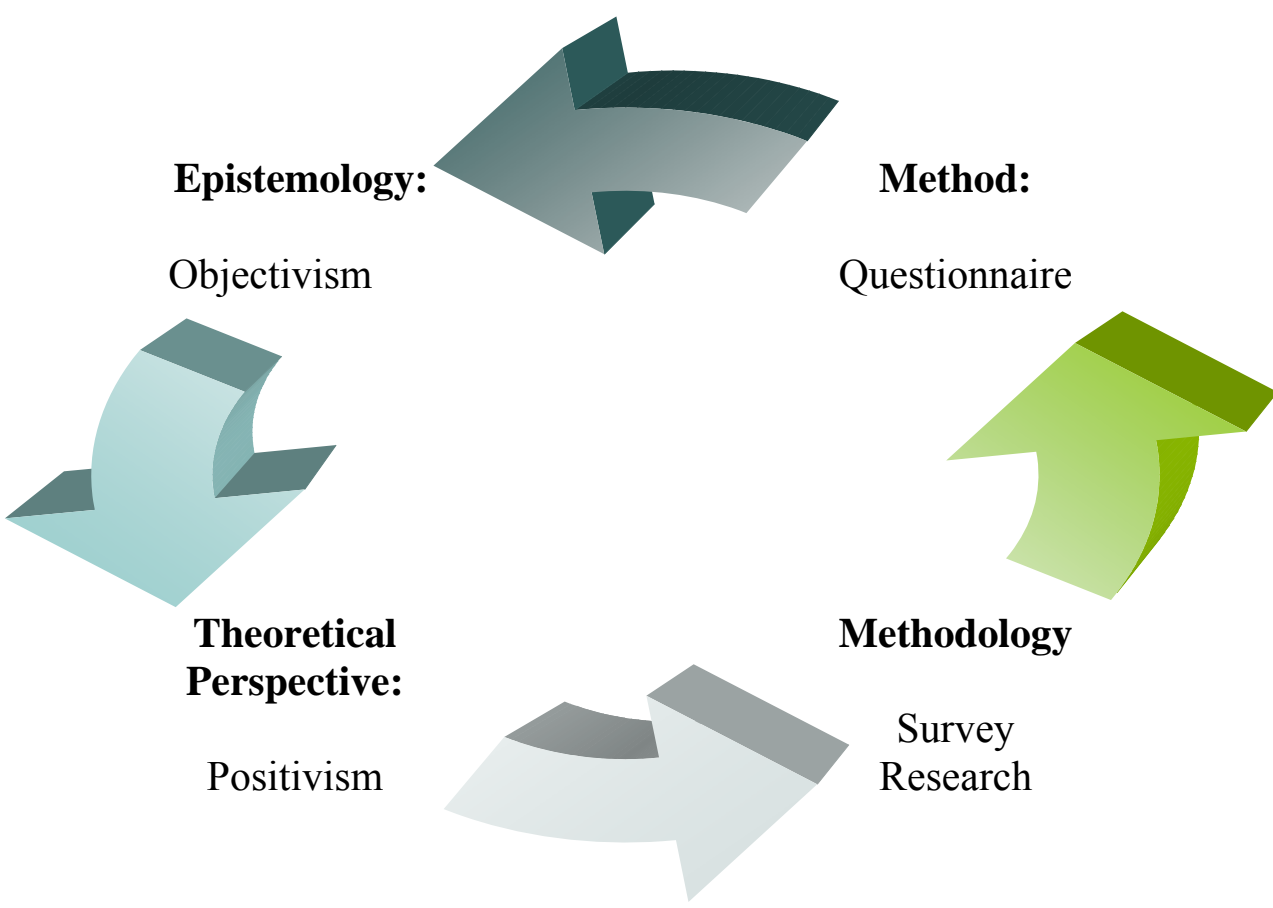


The chosen data collection method was a self-administered questionnaire, commonly associated with survey based research. Depending on the design and lay-out of the questionnaire this type of research tool is easy to comprehend and it provides the participants with a sense of 'safety-in-numbers' as the use of questionnaires can ensure that the participants remain unidentifiable as their specific answers remain anonymous (Cozby, 2004). Another positive aspect of this particular method is that it offers a reduced risk of researcher bias. It was assumed that it would be easier for the students to disclose their attitudes and observations to a stranger than to their teachers. I was not known by the students and I assured them that I had no affiliation with their school, therefore providing them with an opportunity to be open and honest with their responses. Their respective teachers had no opportunity to see any of their individual responses, as I facilitated the complete data collection process myself. Another advantage of using anonymous questionnaires is that it allows for a more objective analysis, as the researcher is further removed from the participants (compared to an interview), as I had no idea which particular student the information was coming from.

Cozby (2004) discussed some of the possible restrictions that the employment of a questionnaire based research method might entail. One of the limitations of using a questionnaire is the fact that it is completely reliant on the students' self reporting. This in itself could cause some bias in the ways in which they have answered some or all of the questions. The students might have selected to answer the questions in such a way to make either their school and/or themselves look good, especially with more sensitive questions such as the one regarding how well the students felt they did at school. This is an area that could be regarded as a somewhat sensitive especially if a student is performing below average academically. If only a very small number of students indicated that they did have below average school marks, for example, one has to question the reliability of the other students' responses. It is therefore important to note that an element of respondent bias could have played a part here, at least to some degree. Therefore, my questionnaire design and the method employed for the questionnaire administration was aimed at reducing both respondent and researcher bias. It is important to note that even though these actions were taken in order to minimize these biases, some students' responses might still have been affected by them to some degree. 
Another specific drawback is the possibility that the students might misinterpret the questions. With this in mind, simple, age appropriate language and straightforward questions were used. Each question was short and to the point in order to minimise any confusion that the students might have had. Another possible drawback when using questionnaires is the potential lack of depth to the participant responses (Cozby, 2004). In order to reduce the risk of this happening, I included a number of open ended questions (with ample space for the students' responses) into the design of the questionnaire, which provided an opportunity for the students to explain and justify some of their responses. Another precaution that was taken in order to minimize this possible disadvantage was that I was present while the questionnaires were being completed and the students were able to direct any specific queries and questions directly to me.

Davidson and Tolich (1999) discussed the advantages of making use of open ended questions, as they enrich the data with unforced opinions, enabling the students to qualify their responses. It is important however, to note that a possible drawback of employing these open ended qualitative comments is that it can lead to questionable validity with regards to those specific responses. Closed questions also have some advantages, which include the ability to speed up the completion of the questionnaire, because the participants only had to tick a box or circle a suited response, and it is easier for the researcher to code and quantify responses. In order to optimise the use of a questionnaire, I employed both closed and open ended questions in the questionnaire.

\section{The Pilot Study}

In order to eliminate or reduce possible errors with regards to the design and layout of the questionnaire it was decided to seek advice from an expert before running the pilot study. A well known and respected Research and Policy Analyst working in the Wellington Public Sector was contacted. She was asked to look over the design and framework of the questionnaire in order to pick up and identify any areas that might have been erroneous and/or perplexing to the students. As a result several small 
changes were made. These changes were concerned with the spatial layout of the questionnaire and some minor language adjustments.

I also decided to conduct a pilot study to minimise the chance of any additional problems that might have been missed either by myself or the research expert. The pilot study used a snowball sample to recruit participants, starting with a number of personal contacts. Seventeen children (11 girls and 6 boys) between the ages of 11 and 13 were willing to complete my questionnaire. The pilot sample contained children residing all over New Zealand, with one child in Whangarei and another as far south as Christchurch. Nine of the participants were New Zealanders, whilst the remaining eight came from other parts of the world, including South Africa, the Maldives, England and the United States of America.

One of the aims of the pilot was to detect whether the design of the questionnaire was suited to the designated research sample. Another aim was to see how long it took the children to complete the questionnaire, in order to make the necessary arrangements with the intermediate school where the data collection would take place.

More importantly, the pilot was utilised to determine whether any possible measurement errors (where the participants' responses appear to be erroneous and cannot be used to make comparisons with other participants' responses) could potentially occur. Cozby (2004: 85) explained that any measure that the researcher intends to take consists of two components, namely the true score and the measurement error score. The true score is a self explanatory concept; it is the actual or real score of any given variable, whilst the measurement error score is evident when the measurement of a variable is unreliable. This could have happened where I worded the questions ambiguously. Only one or two of the children in the pilot sample found some of the questions difficult to comprehend and after investigation of these particular cases, I concluded that their invalid responses were attributable to the fact that English was not their first language.

The pilot study participants were asked to record the time it took them to complete the questionnaire. The average time was between 10 and 15 minutes. Overall, the pilot was well received. Some of the participants made suggestions about the layout and 
design, while one participant in particular was very forthcoming about the overall content and structure of the questionnaire. All recommendations were taken into account and additional minor changes were made.

Originally an Auckland based intermediate school was recruited, via a personal contact, for the purposes of data collection for my research. This particular intermediate school consisted mostly of students from a Māori and/or Pacific Island background and English was the second language for a large number of students at that school. Therefore, the questionnaire initially designed for my pilot study took the demographics of the Auckland based school into consideration. The ethnic group categories in the demographical section of the questionnaire, for example, consisted mainly of specific categories of Pacific nationalities including Māori, Tongan, Niuean, Samoan, Cook Island and Fijian.

Subsequently, the Auckland school withdrew from participating due to unforeseeable circumstances and another intermediate school was required. Fortunately I had a family member who was a student at an intermediate school, based in the Waikato district. I contacted the school principal initially over the phone and briefly outlined my research proposal. Following our phone conversation I emailed her an information sheet (See Appendix 1), outlining all my research aims and objectives and the methodology the research would employ. She contacted me after receiving the information sheet and agreed to commit the school to the research. Approval was gained from the Human Ethics Committee to substitute schools after informing them of this change.

Initially I was concerned about my family member's involvement with the school, but as the research process progressed, she was treated only as a fellow participant of the research. I did not discuss any of the research findings or topics with her. My family member did not have access to any of the completed questionnaires. 


\section{My Questionnaire}

All suggestions and recommendations obtained from the subject expert at the Families Commission and the pilot study were taken into consideration during the finalisation of the questionnaire design. Some of the resulting improvements included a change in the ethnic categories. While originally a range of Pacific Nationalities were included with the withdrawal of the Auckland school, this category was collapsed to Pacific Island to reflect the demographic make up of the substitute school.

The final version of the questionnaire (See Appendix 2) consisted of four double-side printed pages. The questions were presented in simple, easy to understand English and a total number of 16 questions were included. Likert-type scales, along with other open ended and closed ended questions were used. Likert scale questions are closed ended questions on a sliding dimension. They consist of a statement from which the participants are required to circle their chosen response based on their level of agreement. This method of questioning was employed in order to speed up questionnaire completion and to provide the students with a range of forced-choice responses.

The questionnaire was created and designed solely for the purposes of this specific research project to explore students' attitudes, thoughts and perceptions about their physical education classes as well as their knowledge of health in a more general sense. The questionnaire also included demographic data, namely age, sex and ethnicity, in order to determine whether there were any preference distinctions between the different age groups (11,12 and 13 year olds), or whether there were any disparities between students from different ethnic groups. Differences based on students' genders were also explored.

Some of the questions were designed in such a manner that they required the students to answer them without the possibility of being neutral (for example: question 13) as it was important to ascertain an opinion. The open ended questions were an opportunity for students to expand on the answer they gave to a previous closed ended question. A space was provided on each questionnaire for me to assign a unique 
number for my personal records and to assist with data checking. As this was an anonymous survey the students were not required to put their names on their questionnaires.

\section{Sample Size and Data Collection}

The sample frame for this research consisted of approximately 350 intermediate aged school students (between the ages of 11 and 13). Students of intermediate school age should be old enough to comprehend the benefits of being physically fit and living an overall healthy lifestyle. They should also be able to identify any problem areas they feel their physical education classes might have. I wanted to target my research to the students themselves as they are not often consulted on the content and structure of their school curriculum. I do not believe that their opinions are sought when changes are made to their subject areas. This study provided an opportunity to all students at the school to have their say, to express their opinions about something that affects them directly and which, according to references in my literature review, might have impacts on other aspects of their lives such as having strong personal relationships, decreased levels of stress and decreased chances of becoming overweight and other overall health benefits.

The simplest and most effective way in which to advise and inform all students and their parents or caregivers about the research was to have an announcement in the school newsletter (See Appendix 3). The school principal assured me that the school newsletter is a commonly used method of communication between the school and the families of the students and that it was a very effective method for introducing my proposed study. As a result of personal communication, between the school principal and myself, it was decided that due to the non-sensitive nature of the questionnaire the school could act in "loco-parentis" in having the research process carried out. However I felt that informing parents via the school newsletter did give them the opportunity to withdraw their children from the research study. The school found that "opting out" is often more effective than "opting in". 
The insert in the school newsletter appeared approximately two weeks prior to the administration of the questionnaires. This allowed ample time for the parents to contact either the school or myself directly if they wanted their child/ren to opt out of the research or to obtain any additional information about the project itself. Neither the school nor I were contacted by any of the parents/caregivers in relation to the research study. All 350 students had consent to participate.

It was explained to all students at the time of administering the questionnaire that they did not have to participate in the research and that once they had completed and handed in their completed questionnaires it was not possible for them to withdraw. As a result, two opportunities were provided for students to be omitted from participating in the research study. Firstly via their parents opting them out or via opting themselves out of the study.

In order to maximise the response rate it was decided to provide a specific in-class time for all the students to complete the questionnaires. By doing this, it allowed me to obtain a higher response rate, because the questionnaires were administered and collected during class time, compared to if the students were asked to complete the questionnaire at home and return it upon completion. The principal of the school agreed to set 20 minutes aside during class time in order for the students to complete the questionnaires.

On the day of the questionnaire administration, it was decided by the principal and her staff that I should undertake the introduction of my study, the administration and collection of the questionnaires myself. A specific time was allocated for me, allowing a 20 minute interval per class, to go around the whole school and to manage the data collection process in a consistent way. Doing it this way ensured anonymity for the students as their respective teachers were not involved at all and did not come into contact with any of the completed questionnaires at any time. It also provided an opportunity for all the students and teachers to raise any queries they had directly to me and which provided me with the opportunity to answers all questions in a consistent manner. 
On the day of the data collection, the school principal took me to the first classroom to introduce me to the teacher and the students. Following this introduction, I introduced my research and allowed a couple of minutes for the class to direct any specific questions to me. I answered all questions and distributed individual questionnaires to each of the students. It was explained to each of the classes that they had 20 minutes in total to complete their questionnaires, which proved to be sufficient. In the special needs class, the teacher read each question out loud and asked the teacher aides present ( 4 in total) to assist the students with their answers, which did take longer.

Initially I was a little concerned about this, since I did not want the teachers' involvement when the students were completing their questionnaires. However, I noticed that the students were very co-operative and forthcoming about their opinions and the assistance of the teacher aides did not appear to interfere with their responses. Upon completion I collected all the questionnaires and kept each class's questionnaires in a separate, sealed envelope. This assured students that their responses were kept anonymous and private and that it was not possible for them to be identified. I kept all completed questionnaires secure from the day of data collection onwards, and no other person, except for me, had access to them.

\section{Data Analysis}

The completed questionnaires, all marked with a unique number, were scored and loaded onto a spreadsheet for the statistical analysis and interpretation. The data was entered into the Statistical Package for Social Sciences (SPSS, version 15.0). The SPSS package was selected as it had its origin in the social sciences. The package has "the most comprehensive and widely used scientific and survey research product lines available" according to the website (www.spss.com). The package is able to collate and analyse critical data. Each of the open ended questions was coded in a separate spread sheet before combining it with the rest of the data. The statistical analysis for all data in this study was conducted on a personal HP 8805 computer. 
The statistical calculations conducted consisted of basic descriptive statistical analysis, frequency tables, contingency tables and Pearson chi squares tests. The questionnaire also included basic demographic data, namely age, sex and ethnicity in order to determine whether there were any preference distinctions between the different age groups (11, 12 and 13 year olds). Or whether there were any disparities between students from different ethnic groups. Differences based on students' genders were also explored.

Frequency tables were utilised where the number of individual responses for each question was counted and presented in table format. The second statistical calculative tool employed were contingency tables (also referred to as cross tabulations). The strength of a relationship between two or more categorical variables (either nominal or ordinal) can be measured with this basic statistical tool. Contingency tables were employed when the data consisted of two or more categorical variables and I wanted to determine whether these variables were independent or whether a possible relationship existed between them.

Pearson chi square tests were utilised as tests of significance. The chi square test can be utilized for any statistical hypothesis testing. These tests measure the divergence between observed cell counts and what one would expect if the rows and columns were not associated with each other.

The data obtained for this thesis is a descriptive snapshot in its nature, describing the perceptions the students had at the specific time, about their experiences of their physical education classes. It is however important to note that even though my intentions are to make generalisations (to a certain degree) about how the students from this particular school feel about their physical education classes, the data obtained will not be inferential in the sense that it can be used to generalise to all schools within New Zealand. In order for this data to become inferential, further research would need to be carried out using a properly drawn random sample of intermediate schools throughout the country. 


\section{Ethical Reflections}

Ethical approval was obtained from the Human Ethics Committee at the Victoria University of Wellington. This project was therefore guided directly by ethical principles, including: giving everybody involved truthful information about the study, providing an opportunity to all involved to obtain additional information, to ask questions or to opt out of the research; and to respect the participants' confidentiality. An ethical aspect that had to be considered when I undertook this particular research project was that I was working with youth. Even though my chosen topic is not really sensitive in nature I had to ensure that all possible participants, their families and the intermediate school in question, were completely and correctly informed about the project. While the parents or caregivers were given an opportunity to opt their children out of the research, it had to be made clear to the students themselves that they could also opt out if they wanted to. It was important to emphasise to all students that they would not be punished or disadvantaged in any way, shape or form if they decided not to participate in this study.

A possible ethical concern, in hindsight, is that in the absence of "opting out" (either by the parents and/or students), it did not necessarily mean that the parents and/or students were giving their consent or "opting in". Another concern is the possibility that some of the students lost their school newsletters, in which my study was announced, which meant that their parents did not know about the study and could therefore not opt their child/ren out of the study if they so desired. I still used the newsletter as a way to publicize my proposed study as it was the quickest way I could reach all parents at once. 


\section{CHAPTER 4: RESULTS AND DISCUSSION}

\section{Profile of the Participants}

In total 336 intermediate aged students participated in this research. The response rate was $100 \%$ as every student that was offered a questionnaire completed and returned it during class time on the day of the data collection. The average age of the students was 12 years. The gender distribution of the sample was almost equal. Male students represented $51 \%$ of the group, while female students represented $48 \%$ of the sample group (two students did not specify their gender).

The distribution of the sample according to ethnic groups is uneven. The majority of the students (70\%) identified as New Zealand European, while 10\% identified as Māori. The remaining participants came from a mixture of ethnic groups which included students from Britain, the Pacific, South Africa and other ethnicities (See Table 2 and 3 in Appendix 4).

\section{Quantity of Physical Education at School}

The majority of students (89\%, See Table 4 in Appendix 4) reported that they would like to have more physical education classes at school. This was slightly more evident amongst the boys, as a higher percentage of girls (13\% compared to the boys' $9 \%$ ) did not feel the need for any additional physical education classes. In order to see whether these findings between males and females were statistically significant, a Pearsons chi square test was formulated. The findings of the Pearson chi square indicated that there was no significant differences between the genders, $\chi^{2}(1, N=$ $336)=.135, \mathrm{p}>.05$. 
The students were also asked to explain why they felt that they would like (or would not like) more PE at school. The students who indicated they would like more physical education included general comments about not having enough PE at school (22\%); wanting more PE because it is fun (43\%) and wanting more PE as it helps with their fitness and/or overall health (24\%). Some of the comments expressing this view were:

"We hardly have any PE at school"

"PE is good for your health"

"I love PE, because it is fun!"

Only $11 \%$ of the total sample group of students indicated that they did not want more PE at their school. This group of students can be clustered into two subgroups. The smallest group (consisting of 3\% of the boys and $6 \%$ of the girls) felt that they had enough physical education already. The second subgroup of students (consisting of $5 \%$ of the boys and $7 \%$ of the girls) indicated that they disliked PE. Some of the comments illustrating their views were:

\author{
"I really don't like PE" \\ "We already have enough" \\ "PE is boring"
}

These findings match those of previous research (for example; Hamlin \& Ross, 2005) which suggested that boys are more physically active compared to girls. It was expected that boys would prefer to do more physical education compared to girls, but I did however expect the boys to feel even more strongly about an increase in PE classes compared to the girls (though $87 \%$ of girls also opted for more physical education classes). The fact that there were not greater, statistically significant differences between the sexes, as previous literature (Davis, 2003) has suggested, 
could be attributed to a number of factors. This specific intermediate school is very health and fitness oriented which could be one of the reasons why such a high percentage of girls also wanted more PE classes. Another possible reason for such a large percentage of girls wanting more PE is that they might be afraid of gaining weight or becoming fat (this particular issue is discussed in more detail at the end of this chapter).

Sherar, Esliger, Baxter-Jones and Tremblay (2007) explored several reasons for gender differences, which included the fact that girls mature (both in a physical and an emotional sense) approximately two years before their pre-adolescent male counterparts. Therefore girls might consider it immature or childish to run around during play. This accords with Davis' (2003) findings which highlighted that boys of the sample age still prefer more physical types of play for example rugby or soccer and are generally more inquisitive. I can therefore conclude, as a result of previous research findings, discussed above and from my data that girls of this age tend to take part in more sedentary types of activities such as socialising in small groups.

The literature reviewed (Push Play Campaign, 2003; \& Kahan, 2008) suggested that the required level of physical activity for students of these ages is approximately 30 to 60 minutes of moderate intensity exercise every day. Research (Malina, 2001) suggests that physical activity is likely to decrease across one's lifespan, but the biggest decrease of physical activity is evident when adolescence is reached, which is approximately when the students go to college. It is also known that the older a child gets the less active they tend to become (Sherar et al., 2007) and thus students are less active at college compared to intermediate school (Hill \& Cleven, 2005 in Hill \& Hannon, 2008; \& Sallis et al., 2000 in Hill \& Hannon, 2008). Data from my case study supports this contention as a statistically significant difference was found between the 12 year old age group and the 13 year old age group. Pearsons chi square confirmed that a larger percentage of 12 year olds compared to 13 year olds wanted more PE at their school, $\chi^{2}(1, \mathrm{~N}=336)=.013, \mathrm{p}<.05$.

Physical education classes could be providing the only opportunity, environment and time for some students at this school to engage in physical activities. Researchers 
have suggested that this would especially be the case for children from families of a lower socio-economic status (Cerin \& Leslie, 2008; \& Sallis et al., 1999) which would include Māori and Pacific children as they are over represented in this category within New Zealand (Hamlin \& Ross, 2005). In my study, the majority of Māori students $(88 \%)$ and half of the Pacific students indicated that they would like more PE at school, Pearson chi square results confirmed that there was no significant differences between the different ethnic groups and wanting more PE at the school, $\chi^{2}(1, N=336)=.279, p>.05$. These findings are somewhat contradictory to other research findings such as Hamlin and Ross (2005); Shilton and Brown (2004, in Hamlin \& Ross, 2005) who argued that Māori and Pacific students are likely to opt for more inactive type lifestyles compared to other ethnic groups.

Another related concern with regards to the increase of sedentary lifestyles amongst adolescent girls in general; people living in lower socio-economic situations and some Māori and/or Pacific people, is that New Zealand children, generally are increasingly suffering from obesity related illnesses. (Hamlin \& Ross, 2005). This means that life threatening illnesses such as coronary heart disease and diabetes are increasing especially amongst adolescent aged children (Berenson, 2002, in Schofield et al., 2005). It is therefore important that our schools ensure that the time allowed for physical education is not only used optimally but is also presented to the students on a regular basis. Beyer (2008) stressed the importance of optimal use of time spent in physical education by suggesting that children need to be active, resulting in them having elevated heart rates for at least $50 \%$ of the time they spend in their physical education classes, if the duration of the class is 60 minutes. The intermediate school where my research took place offers physical education for 45 minutes once a week. However, the school also timetables one 45 minute sport education session once a week and two weekly 20 minute fitness sessions.

Even though this particular school does offer a variety of different opportunities each week for their students to be physically active, it is important to note how much of that time the students are actually engaged in good quality physical activity. The outlined curriculum and the actual pedagogical practices might not be consistent. If used optimally, a 45 minute session of PE once a week, will only give the students 
approximately 30 minutes of being physically active at school every week. But, with the two fitness sessions and the additional 45 minute sport education session every week, I do feel that this school's ethos is instilling and emphasizing the need for physically fit and active lifestyles. This gives rise to the question of: how much physical education is actually enough? Stephan Virgilio (2009) argued that two 30 minute physical education sessions a week is inadequate as it does not enable the physical educator to make significant adjustments and improvements to the students' cognitive, emotional or kinetic type behaviours. Having half an hour PE sessions, can be a waste of time. The time spent in the dressing room and getting the students organized will take up approximately 15 minutes of each class. The remaining 15 minutes of the class time is simply not enough to work towards moderate to vigorous levels of physical activity.

In total this particular school provides 130 minutes of physical activity during school time for their students on a weekly basis. The school also strongly urges its students to participate in at least one extra curricular form of sport. These extra curricular sport sessions occur a couple of times a week for the duration of an hour or an hour and a half and are usually followed by a match between teams from different schools over the weekend.

Another extraneous factor that might affect the actual amount of physical education training the students receive is the weather. If a school only has their PE outdoors, the weather might play a big role in the actual amount of physical education the students receive. The school used for my research indicated that the weather does affect their physical education teaching to some degree, but that the teachers try to work around it. If it is raining on a scheduled PE day, and the school hall is not available for an indoor physical education session, the teachers might move their PE to another day.

\section{Level of Choice}

Only a very small percentage of students (4\%, See Table 5 in Appendix 4) felt that they always had a choice as to the types of activities they did during their PE classes. 
The vast majority of students felt that they were given a choice only occasionally $(84 \%)$ or never $(12 \%)$. This particular school does have a dedicated Physical Education Department, but the respective class teachers that teach PE are handed a year plan that outlines the physical education activities and objectives for the year. The types of activities the students engage in and the level of choice they have is therefore determined by each individual PE teacher.

The effects of implementing a choice based physical education programme can be far reaching as the literature revealed. The aim of this type of programme is to promote fun physical activities, to increase the level of participation which in turn could have favourable effects on students' other school activities including their academic performances. Some of the intermediate school teachers might have allowed the students to have more choice compared to others. For example, the $12 \%$ of students who indicated that they never had a choice with regards to the types of physical activities, could have all been students from the same classes. This is another possible indication of how different pedagogical practices can change and affect students' actual curricular interaction and perceptions. While $84 \%$ of the students indicated that they did have some level of choice regarding the types of activities they participated in, this does not illuminate the extent and range of those choices. Their choices might have been limited to a choice between two types of physical activities for example or it could have been limited to having a choice in the activities only one day per term. The question did not measure the extent or the effects of the choices the students had. Neither did it examine the students' perceptions about having choice.

The literature explored discussed the numerous advantages that the role of choice plays within the physical education curriculum. To recap some of the outlined advantages: students value choice and if they have the opportunity to offer their opinions and make changes and suggestions to the types of activities they take part in during their PE classes it will be more beneficial to them. When the students who participated in this study were asked to provide any additional comments about their PE classes, five percent made a comment or suggestion about having more choice regarding the types of activities they participated in. Some of these types of comments included: 


\section{"I want to choose some games for PE"}

“We never have a say about what we can do in PE"

"Its fun when my teacher asks the class what we want to do for PE"

These results suggest that students enjoy being able to make suggestions and recommendations about the types of activities for their PE classes, and other research also stressed the importance of enjoyment especially for PE learning (Cothran \& Ennis, 1998 in Williams \& Germain, 2007; \& Ennis, 2008). When asked directly $96 \%$ of the students indicated that they really like or like PE, whilst an additional $22 \%$ mentioned how much fun their PE classes were when asked for additional comments. Giving the students a choice of activities will not only be beneficial to the students themselves, but it will also be useful to the teachers as it will encourage an increased level of participation amongst the students, which could improve behavioural issues in PE class time. Personally, I feel that schools, teachers, parents and even policy makers cannot ignore these far reaching effects that the implementation of a choice based PE programme can have on a student's level of participation and enjoyment within their PE class.

Former research (see Chambers, 1991; Headley, 2001; \& Blakemore, 2003) has suggested that the implementation of a choice based PE programme is effective in increasing student participation. According to some of the students at this particular school, the choice based programme is not implemented at their school. I conjecture that a possible reason for not implementing this type of programme at this school is due to the fact that schools generally do not take the students' perceptions, and interests into account when constructing their PE curriculum. Another possible reason why a choice based PE programme has not yet been implemented within this schools' outlined physical education year plan, is because it would result in change not only for the current pedagogy of physical education, its systems and procedures but would also result in the transformation of the overall curricular framework of physical education. Other reasons for not implementing a choice based physical education programme could include financial restrictions as there might be limitations 
in access to equipment and other resources that might become necessary once a choice based PE curriculum has been implemented. These changes could potentially broaden the physical education curricula as the students themselves make suggestions about different types of activities they might engage in. The employment of a choice based physical education programme has far reaching effects as it empowers the students by giving them some decision making authority and by giving them ownership of their own curriculum. This notion goes against traditional teaching methods and that could well be another reason why this particular school has not taken the choice based programme on board.

A choice based programme can be adjusted in order to include other curriculum subject areas and skills activities that the students must become competent in, in order to pass the standard requirements. Providing the students with an element of choice will ensure that their opinions can be heard. The teachers should encourage all students to voice their opinions and ensure that there are a variety of activities available to them. A basic understanding and respect between students and teachers is needed in order to uphold the standard of such classes. Smith (2005) stated that teachers should not see the introduction of choice to the PE class as a surrendering of their teacher's control. The provision of choice will empower the students to a certain degree, but it will also increase their levels of ownership and ultimately increase their levels of learning. As a result, the students will have increased confidence, self esteem, development of social skills, including communication, taking turns, praising and acceptance of feedback, and they will feel more comfortable with their chosen physical activities. The key here is to emphasise to the school and its teachers that it is possible for them to successfully implement and manage this type of programme.

Since choice based programmes consist of dynamic, goal oriented, collective and controlled learning, it is important that the school and its teachers manage such a programme successfully. Pagnano and Griffin (2001) highlighted four key aspects that need to be taken into consideration when employing a choice programme, the programme must have specific student aspirations outlined (in terms of skill acquirement); secondly the students must make use of multiple methods and approaches in order to achieve their outlined goals; thirdly rules and regulations must 
be in place in order to maintain structure and discipline at all times and finally learning should take place through the employment of fitting evaluative tools. The notion of choice is not limited to the type of activities the students might decide on. This type of programme can also be used to determine the students' choice of partners and/or teams; equipment, degree of physical activity difficulty and even when they would like to have PE, providing that it does not cause structural problems in terms of timetabling space, equipment and other resource requirements. In order to ensure that all students benefit from a choice based programme, it is important to implement it in such a way that all students have an opportunity to exercise their own choice. This can be done, for example, by asking all students to write a physical activity of their choice on a piece of paper, the results could be tallied and the most popular activity nominated would be executed. The same principle can be used for example, to pick a PE day or to pick team members.

A choice based PE programme can be seen as even more beneficial to those students who dislike physical education (Condon \& Collier, 2002). The choice based physical education programme could directly decrease challenging behaviour amongst those students who are currently not interested in taking part in the physical activities outlined in the physical education curriculum $(4 \%$ of students indicated that they dislike or really dislike PE at their school.

Students with higher needs, which include both students who are physically less able and those students who excel in physical activity, can especially benefit from a choice based programme. Through the employment of this programme the curriculum can be adjusted to meet the needs of all students. Getting students, especially preadolescents and adolescents, motivated to become and to stay physically active is no mean feat, but research (for example; Pagnano \& Griffin, 2001; \& Smith, 2005) suggested that choice is important to students and it can aid their commitment to leading physically active lifestyles. The students of this school are more likely to tolerate an activity of their choice, compared to an activity that they had no choice in. Schools should implement the notion of choice from an early age, since the literature (Lambert, 1997 in Condon \& Collier, 2002) suggested that providing students with choice in physical education from a young age could potentially contribute to them making healthier lifestyle choices throughout their lifespan. 


\section{Physical Fitness and Academic Performance}

Overall, a small number of students (13 in total), $3 \%$ of the males and $5 \%$ of females (See Table 5 in Appendix 4) indicated that they disliked physical education. A very small percentage of the students indicated they perform below average academically, $3.5 \%$ of the males and $3.6 \%$ of the females. Sixteen percent of the males and $20 \%$ of the females indicated that they were not aware of the association between physical fitness and academic performance. However, a larger proportion of students indicated that they disliked going to school, $30 \%$ of the males and $11 \%$ of the females.

Students who indicated they disliked participating in their physical education classes also indicated that they did not do very well academically. In my opinion these students were also less likely to know about and understand the apparent correlation between physical fitness levels and academic performance and I believe they were more likely to have an aversion to attending school in general. Pearson chi square tests confirmed this, $\chi^{2}(1, \mathrm{~N}=336)=.004, \mathrm{p}<.05$.

In general boys dislike attending school more compared to girls (Hallinan, 2008). There could be a number of possible reasons for this. Academic achievement could influence one's perspective of school attendance and since the boys indicated they do (only slightly) worse in comparison to the girls in their school marks (36\% of the boys indicated their school marks were average or below average, compared to $34 \%$ of the girls who indicated their school marks were average or below average) they are more likely to dislike attending school compared to girls. Student-teacher relationships could also affect these students' perceptions of school attendance. Wilson (2003) described boys and girls of a pre-adolescent age as being intrinsically different from each other with regards to their behavioural patterns, social relationship building and levels of academic commitment. These differences result in teachers acting and responding towards boys and girls in innately different ways. Boys are generally more boisterous and disruptive due to shorter attention spans compared to their female counterparts (Wilson, 2003). Therefore the assumption can be made that the relationships between teachers and boys are generally more stressful which could lead 
to a lower level of enjoyment at school, resulting in the boys disliking attending school at an elevated rate compared to girls.

It is evident from the above results that the associations between academic achievement, physical fitness levels and school attendance are complex and dynamically interrelated concepts. Research has pointed out the numerous confounding and extraneous variables that need to be factored in when looking at PE and its affects on student wellbeing in a general sense (Chambers, 1991; Sallis et al., 1999; \& Bailey, 2006). The aim here is not for me to draw conclusions about these causal relationships. Rather the intention is to determine whether the students were aware of these correlations, whether they comprehended the wider effects of leading physically fit and healthy lifestyles and to discuss some of the variables that might factor into the students' academic performances, such as their physical education perceptions and their knowledge (or lack thereof) of the connection between physically active lifestyles and their school marks. From the results it is apparent that the majority of students are aware of the wider effects of physical fitness and wellbeing and those students appear to be reaping the benefits. The students are well informed about the benefits of physical wellbeing, including that it can affect their school grades. An overwhelming majority of the students ( $96 \%$ of the males and $97 \%$ of the females) indicated that learning about health, in a general sense is useful to them.

The results obtained from my questionnaire are supported by the reviewed literature. Students who are physically fit do tend to perform better academically and seem to be happier and more content in other areas of their lives, compared to students who are unfit and/or unhealthy (for example; Taras, 2005). The downside of these findings is that there are a number of students $(17.5 \%)$ who did not know that their physical fitness and wellbeing can affect their academic performance. It is possible that at least some of these students lead physically fit lifestyles and have therefore never considered the effects that an unfit lifestyle might have on their school marks. Alternatively, some of these students are physically unfit, and unhappy in other areas of their lives (such as trouble with their interpersonal relationships, weight issues or a troubled family life, for example) and therefore thought that there were other (maybe more valid) reasons for them to under achieve at school. Another possible reason for 
these students' lack of knowledge regarding the association between physical fitness and academic performance could be that some of the $17.5 \%$ of students might have been in the special needs classes. The children in these classes are performing well below average in a number of areas, academically and/or physically and this might be the reason why they are not aware of the possible effects of health and fitness on their school grades.

On a more positive side, a total of $82.5 \%$ of the students $(84 \%$ of the males and $80 \%$ of the females) indicated that they were aware that their physical education classes contribute positively (either A lot or Somewhat) to other areas of their lives. Students in these pre- adolescent age groups should know that health and physical wellness is a multifaceted, far reaching concept and that being unhealthy can potentially have detrimental effects on them either physically, socially and/or psychologically (Headley, 2005; \& Taras, 2005).

Sixty-three percent of the students indicated that they learn enough about health in their physical education class. The students might also be learning more about health in other subject areas confounding this result. Health is such a broad topic, and it is important to teach and educate children about the effects of physical activity on their personal health. This particular school does promote and educate their students on the far reaching effects of living physically fit and well balanced lives as this quote clearly illustrates:

"The importance of the physical wellbeing of our students is well catered for in the extensive Fitness and Physical Education programme."

(Intermediate School Website, 12/06/09)

\section{Range of Physical Activities}

Seventeen percent (See Table 6 in Appendix 4) of the students commented about the need to have more diverse types of activities for their physical education classes. Several comments were made about "boring" activities that were often weather 
dependent. Students indicated that they would like to do "less running" and have "more games" and other types of physical activities for their physical education classes. Twelve percent of the students (13\% of males and $11 \%$ of females) indicated that they had never had a say in the types of activities they did in their physical education classes.

Students were also asked how they felt about doing activities in their physical education classes that they have not tried before. A majority (58\%) indicated that they enjoyed trying new activities in their PE classes (64\% of the boys and 52\% of the girls). Some students indicated that they do not mind attempting new activities $(39 \%$ in total, $34 \%$ of the boys and $45 \%$ of the girls). Only a very small number of students (3\%) specified that they disliked trying new activities in their PE classes (1\% of the boys and $3 \%$ of the girls).

These types of results are also in support of having a more diverse range of activities present within the physical education curriculum as there is a greater likelihood that students will enjoy having the opportunity to try out new activities that other students might have suggested. This could also help prevent the students from getting bored with their physical education curriculum as it is evident from the results that they like the challenge of trying out a new type of activity.

This finding also illustrates the close knit relationship between choice and the types and diversity of physical activities. If the students had more choice with regards to the types of activities they took part in during their PE classes, the diversity or range of activities would probably have been much larger. As for the results obtained, regarding the students' level of choice, these particular findings are also dependent on the respective teacher's curricular execution practices. Some teachers might use a wide variety of physical activities within their PE class, whilst others might only use a few activities repeatedly.

Other research clearly state the importance of having a diverse range of activities within the physical education curriculum (for example; Smith, 2005) to cater for different levels of competencies. Different types of activities could be beneficial to the students as some activities might be more of a challenge to some students 
compared to others, which means that students' abilities are being tested more. Smith's (2004) study found that students are more likely to have a positive perception about their physical education class when their school employed a variety of physical activities and having a diverse range of activities was ranked the highest by almost all of the students, followed by other aspects such as; the students' relationships with their PE teacher; having fun and excelling in the physical activity.

Students are more likely to be focussed and interested in physical education if there are a variety of activities that challenge the students on many different types of physical and mental exercises. Some students (17\%) stated their opinions on this matter without being directly prompted, which indicates that there is a need for this school to review the types and range of activities that some of its teachers are using in their physical education classes. Darst, Pangrazi and Stillwell (1995) stated that the goal of the physical education curriculum is to educate the students about physical fitness and wellbeing and that this goal can be reached by encouraging the students to take part in a variety of different physical activities in order to find those types of activities that are personally attractive to the students themselves. The students are more likely to maintain a physically active lifestyle if they found an activity that best suits them.

It would appear that one of the biggest barriers to motivating and increasing student participation in physical education is the students' apparent lack of interest. By providing these students with choice and by presenting them with a variety of activities the school will be able to overcome this obstacle. This particular school commented (on their website) that they offer a wide and interesting variety of physical activities to their students. Once again, it comes down to what types of activities, resources and equipment the respective teachers actually make use of.

Numerous alternative types of activities have been explored within the literature (see Hill and Hannon, 2008). Activities such as frisbee, volleyball, dodge ball, climbing activities and some forms of dance have been discussed. Another type of physical activity would be touch rugby, which is socially very acceptable within New Zealand schools, it does not involve a lot of equipment or resources, and it could be fun for both sexes. Touch rugby is collision free and safe; it involves vigorous running, 
continuous movement and hand-eye coordination which provide the students with energetic cardiac exercise and team-building opportunities.

The school in question does offer a variety of activities to its students, including ball sports (such as rugby, netball, and soccer), dancing (ballroom lessons, hip hop classes) and swimming (summer only). The important aspect here is to investigate which activities the students are participating in the most, and if they actually participate in all the different types of activities that are available to them. Pedagogical practices, weather, student preferences and their level of choice can have far reaching effects on their level of participation in the diversity of activities presented to them.

Hill and Hannon (2008) conducted a study in which they asked some students what types of activities they would like included in their PE curriculum. The students nominated dodge ball, dancing, rock climbing, martial arts, and trampolineing as activities that they would have liked to be included in their PE curriculum. There are a vast range of physical activities, all of which have their own advantages and require their own amount of time and resources. With the above mentioned activities it is also important that the school take into consideration the age appropriateness of each of these activities.

\section{Other Physical Education Aspects to Consider}

Another aspect, highlighted in the literature review is the importance of the fun and enjoyment element regarding student participation in physical activities (Williams \& Germain, 2008). An assumption can be made that the more fun one has within a certain domain (for example art, sport or academics) the more likely one is to excel in that domain, compared to other areas. The students were asked what their favourite subject was at school, $34 \%$ of the students indicated that PE was their favourite subject. Reasons given for this included, that PE was fun (76\%), that PE increased their fitness levels (13\%), that they enjoyed being outside $(6 \%)$ and a final reason for why PE was their favourite subject was because they felt that they were good at it 
(5\%). The students were also asked how well they think they are in participating in $\mathrm{PE}$ and their answers suggested that boys thought that they were better at doing PE (76\%) compared to their female counterparts (61\%). Girls were more likely to rate their performance in physical education as average (33\%), poor or very poor $(6 \%)$ compared to the boys who see themselves as average (23\%), poor or very poor $(0.6 \%)$.

Students were also asked how much they liked doing exercise in their own time when they were not at school. Although this question could have been formulated more appropriately the findings suggested that there were not really any gender differences, as $84 \%$ of the boys indicated that they do exercise $a$ lot or somewhat compared to $88 \%$ of the girls. These findings appear to contradict some of the literature which stated that girls are less active in this age group compared to boys (Hamlin and Ross, 2005), but as there was some ambiguity around the wording of this question it is not possible to draw a definite conclusion about this particular aspect.

\section{Fear of Becoming Fat}

A concerning theme became apparent whilst doing the basic data analysis. A seemingly large number of girls (18\%) and boys (12\%) (See Table 8 in Appendix 4) responded to the question: "Why do you want to keep doing PE when you are older?" by stating that they would continue doing PE when they are older only because they are scared of becoming fat. (I am aware that PE is an institutionalised form of physical activity, the aim of this particular question was to determine whether students would continue to take PE as a subject once they reach secondary school.) This means that these pre-adolescents will engage in institutionalised physical activity not to improve their health, but solely out of the fear of becoming fat. Some of the comments made included: 
"I will do PE when I am older because I am scared of getting fat" (female)

“I might get fat if I stop doing PE” (male)

"I don't want to be fat" (female)

The literature revealed that this is an increasingly worrying trend within western society (French et al., 1994; Cherry, 1996; \& Gilbert, 1999). Wills, Backett-Milburn, Gregory and Lawton (2006) described the perceptions that adolescents have with regards to being overweight as very complex and often contradictory. They found that adolescents who were classified as being overweight and obese were more likely to accept their body image compared to those adolescents who were classified as being in the 'normal' weight range. Adolescents who were classified as having a 'normal' weight were more likely to be anxious about their overall weight and body image and would often attempt to lose weight as they were not satisfied with the way they looked.

The effects of this fear can be far reaching and even dangerous as Cherry (1996) pointed out. She stated that this inherent fear that young people have about their body images and their weight in particular could lead to dangerous kinds of behaviours, including crash dieting and purging which could lead to the development of eating disorders in some cases.

As my findings suggest, this is not only evident amongst pre-adolescent girls, boys are also subject to this apparent fear of becoming fat. Frost (2003 in Wills et al., 2006) also found that boys of this age place great emphasis on their appearances. Frost argues that boys and girls fear fatness for different reasons; girls for example fear fatness because of social pressures (such as going clothes shopping with their friends) whilst boys fear fatness due to personal or individual pressures (noticing that their excess weight is slowing them down in their physical play with other males). The different sexes also exhibit different types of behaviours in controlling their weights. Wills et al., (2006) stated that boys will attempt weight loss through safer means and methods compared to girls. Boys are likely to increase their level of 
physical activity and attempt to eat more healthily where girls will resort to more risky types of weight loss methods, such as crash dieting, purging or ceasing eating. It is these types of methods that girls employ to lose weight that will make them more vulnerable to develop eating disorders compared to boys. Girls are also more at risk as they can have more distorted self images (Sweeting \& West, 2002, in Wills et al., 2006). Girls are more likely to succeed in losing weight through risky behaviours, resulting in an emotional high and a sense of achievement which could reinforce such behaviours even more.

There are several possible reasons for this seemingly irrational fear of being fat, including the fear of being bullied or teased. Research (Janssen, Craig, Boyce \& Pickett, 2004 in Wills et al., 2006) has shown that children who are overweight and obese are more likely to be the victims of bullying and teasing compared to children with normal weight. The students will be aware of this as they generally know who the victims of bullies are. I believe that the fear of fatness is therefore the result of other, maybe more subconscious, fears, such as social rejection and harassment from other students. Another possible related fear is that the students who are overweight or obese are less likely to have a lot of friends (Strauss \& Pollack, 2003 in Wills et al., 2006). Once again the students at this school will be aware of this and the fear of being unpopular, especially during the pre-adolescent and adolescent years might result in the fear of fatness.

Of those students who indicated that they would continue doing PE when they are older only out of the fear of fatness, 70\% identified as New Zealand European, 12.5\% as having a British ethnicity and 9\% were classified as Māori. This fear of fatness was described as being mostly evident amongst Western cultures as it is a western custom to be thin. Obesity is seen as repugnant within our western society (Frost, 2001 in Wills et al., 2006). Being fat or overweight is therefore seen as being outside of the societal norms and my research supports this.

In the next chapter I discuss the way in which the research aim and objectives were met. Several suggestions and recommendations will also be made to the school in question regarding the structure and facilitation of their physical education curriculum. 


\section{CHAPTER 5: CONCLUSIONS AND RECOMMENDATIONS}

My research set out to ascertain pre-adolescent opinions of physical education using a New Zealand Intermediate school as a case study. This study confirmed that the students were generally willing to share their views and experiences of their physical education classes. Based on their responses, there were several aspects of the PE classes at their school which they would like to have reviewed in order to maximise their levels of enjoyment and participation.

This thesis asserted that it is crucial for schools to consider the affects of curriculum content and pedagogical practices on students' levels of enjoyment and active participation in their PE classes. Outside of the school environment, parents and the wider society need to appreciate and take into consideration what students have to say about course content and pedagogical practices, especially since research has shown that these factors can greatly affect students' level of participation in PE, especially since participation in regular, good quality physical education can have positive effects on various spheres of students' lives. Students place a high priority on the enjoyment factor and the majority of students would like to increase their level of participation in their physical education classes.

The quantity of PE classes offered to students, the level of choice students have, the range of physical activities available to students and the physical, social, cognitive and psychological effects of student participation in good quality physical education classes have all been explored. The students felt that an increase in the quantity of PE was necessary; the majority indicated that they do not have a choice with regards to the types of activities they participate in; they made recommendations regarding the types of activities they would like to have more of in their PE classes; and they were mostly aware of the benefits of leading physically active lifestyles. 
I believe it is important for schools, parents and society to be aware of student perceptions on the curriculum content and pedagogical practices of their PE classes as it will allow for open discussion and on-going dialogue about what students value. Students should be able to voice their opinions and express their beliefs regarding something that affects them so directly. Schools, parents and society should be able to provide a space for such expressions of opinions.

\section{Recommendations to the School}

It is hoped that the school will take note of the recommendations and suggestions from this study to potentially increase active student participation in their PE classes. The school is pro-active in their students' physical wellbeing and in the promotion of the benefits of good health in general. I feel it is important that the school continue on with their participation in regional workshops with neighbouring schools which focuses on continual improvement and personal development in teaching strategies. The school utilizes these workshops to their full potential and uses them as a consultative networking tool to create a community based workshop for their teachers in order to evaluate and assess each others' teaching abilities and strategies in PE. By doing this, other schools will also evaluate their own individual physical education pedagogical practices and the schools can share ideas, strategies and possibly even resources and equipment.

The school timetables weekly physical education classes and it also schedules regular sport education sessions and fitness classes during school time in addition to several extra curricular activities. The majority of students opted for an increase in the amount of PE classes they receive, but as it is evident that the school does provide numerous opportunities for students to engage in physical activities (both inside and outside of school), I feel it is unnecessary to make any further recommendations regarding this particular issue.

It is strongly recommended that the school implement a choice based PE programme within the existing physical education curriculum. The implementation should not 
incur any additional costs or resources and will need a minimal amount of planning and facilitation. Research suggests that the students find more enjoyment in such a programme which will lead to a higher level of student participation in their PE classes. The implementation of a choice based programme will increase the chance that the range of physical activities the students has access to will expand. This relates to my next recommendation, that the school review the types and range of physical activities they present to the students. The research clearly outlined the benefits of having a diverse range of activities. If managed effectively, a choice based programme will assist in the instigation of other, more diverse types of physical activities.

Regarding the students' knowledge about the association between physical fitness levels and academic performance I recommend that the school continue on with its current practices. Overall, the students were well informed about the effects of fitness on their general health and wellbeing and potentially on their school marks. I do recommend that the school also aim to educate the parents and the wider community about this association, as this will broaden the support framework for the students.

My final recommendation to the school is to develop questionnaires to continue requesting feedback from their students with regards to their levels of satisfaction with the variety and their level of choice and enjoyment of the physical education curricula. The students will enjoy and appreciate the opportunity to voice their opinions and/or concerns. This will give the school a good indication of whether implementing a choice based programme is successful and whether the students are satisfied with the range of physical activities that are presented to them.

Small scale changes to the physical education curriculum and pedagogical practices at the chosen school could lead to changes in student participation over time. It should not create any further financial or time costs for the school to implement an innovative choice based programme neither would the adoption of a variety of different types of physical activities. 
It is important to note that all recommendations made were based on the conclusions drawn from student responses. Their views might not reflect the actual pedagogical practices and curricular content practiced at the given school.

\section{Possible Strategies and Policy Implications}

I believe that one of the core problems regarding how PE is perceived arises from the fact that $\mathrm{PE}$ is defined in such loose and interchangeable terms, as was discussed in Chapter 2. It is of importance for policy makers, schools and teachers to clearly stipulate and define physical education and distinguish it from the rest of the physical attributes of the school curriculum. Once a clear unambiguous working definition has been agreed upon, and the objectives outlined, students might be able to relate to it more readily and their perceptions and experiences would mirror that. A review of current curricular practices of PE within New Zealand schools could result in significant policy changes.

\section{Reflections on the Research}

The questionnaire and overall research design was successful as it ensured that the outlined research aim and objectives were met. The design could however have been extended in order to get a more in-depth view of each of the objectives. If time and resources had permitted, I would have organised several focus groups not only amongst the students but also amongst some of their teachers in order to include a more qualitative aspect to the research design. In addition I would have liked to include some participant-observation, by sitting in on a few physical education classes, in order to get first hand experience on the way in which students relate to their teachers, their fellow students, the types of activities they have and the students' overall levels of enjoyment and participation. A multi-method approach would have allowed for a more in-depth exploration of the topic. 


\section{Recommendations for Future Research}

This case study can be used as a basis for future research on this particular topic. The specific focus of student perceptions regarding curricular practices is an underresearched area and there is a need for more work on this subject. Getting a clearer idea of how students relate to their physical education curriculum and what their opinions are with regards to certain aspects of their physical education classes would be beneficial to the overall quality of this subject. A modified, upgraded, large scale version of my research would give a clear view of what intermediate (and even other) students have to say about the physical education that they are being taught at their respective schools. It could lead to a more unified, standardised (yet flexible) curriculum that is both fiscally-sound, affordable and highly enjoyable for everyone involved.

In the absence of large scale collection of additional information from other schools, this research has provided a model and framework for a questionnaire that can be adapted by future researchers. I further suggest employing a multi method study for future research, as it would enable researchers to get a more in-depth view of the students' perceptions. A simple questionnaire is not sufficient to explore this topic in depth in other schools across New Zealand. Conducting interviews and/or focus groups, doing participant-observation and presenting students (and their teachers) with further developed questionnaires would enable researchers to get a clearer picture at a national level of the status of New Zealand PE content and pedagogical practices. More evidence from student perceptions and the affects it has on their participation in PE are needed to move on to the next stage of analysing, addressing and resolving issues that might arise. 


\section{BIBLIOGRAPHY}

Bailey, R. (2006): Physical education and sport in schools: A review of benefits and outcomes. Journal of School Health, 76.8, $397-402$.

Barr-Anderson, D.J., Neumark-Sztainer, D., Schmitz, K.H., Ward, D.S., Conway, T. L., Pratt, C., Baggett, C.D., Lytle, L., \& Pate, R.R. (2008): But I like PE: factors associated with enjoyment of physical education class in middle school girls. Research Quarterly for Exercise and Sport, 79.1, 18 - 28.

Bauman, A., McLean, G., Hurdle, D., Walker, S., Boyd, J., van Aalst, I., \& Carr, H. (2003): Evaluation of the national 'Push Play' campaign in New Zealand creating population awareness of physical activity. Journal of the New Zealand Medical Association, 116, 1179, 535 - 544.

Beyer, R. (2008): Restructuring the secondary physical education curriculum to meet new challenges: sharing equipment and a curriculum offers an affordable way to increase students' physical activity. The Journal of Physical Education, Recreation \& Dance, 79.9, 27 - 33.

Blakemore, C.L. (2003): Movement is essential to learning. The Journal of Physical Education, Recreation and Dance, 74.9, 22 - 27.

Block, B.A. (2008): Using iPods in dance pedagogy: Use students' love of technology to your advantage. The Journal of Physical Education, Recreation \& Dance, 79.7, 25 - 29.

Boyce, A.B. (2009): Creating instructional environments that keep students on target. The Journal of Physical Education, Recreation and Dance, 80.1, $49-57$.

Bulger, S.M., Housner, L.D., \& Lee, A.M. (2008): Curriculum alignment: a view from physical education teacher education: professional preparation programs need to adopt more interdisciplinary approaches to curriculum and instruction. The Journal of Physical Education, Recreation \& Dance, 79.7, $44-50$.

Burrows, L., \& Wright, J. (2004): The good life: New Zealand children's perspectives on health and self. Sport, Education and Society, 9, 2, 193 - 205. 
Castelli, D., Hillman, C.H., Buck, S.M., \& Erwin, H.E. (2007): Physical fitness and academic achievement in third - and- fifth - grade students. Journal of Sport and Exercise Psychology, 29, 2: 6 - 12.

Cerin, E., \& Leslie, E. (2008): How socio-economic status contributes to participation in leisure-time physical activity. Social Science and Medicine, 66.12, 2596 2610.

Chambers, S.T. (1991): Factors affecting elementary school students' participation in sports. The Elementary School Journal, 91, 5, 413 - 420.

Cherry, S.S. (1996): Adolescent insecurity increases eating-disorder vulnerability. Fort Worth Star, Telegram, $17^{\text {th }}$ April, Forth Worth, 5.

Chomitz, V.R., Slining, M.M., McGowan, R.J., Mitchell, S.E., Dawson, G.F., \& Hacker, K.A. (2009): Is there a relationship between physical fitness and academic achievement? Positive results from public school children in the Northeastern United States. Journal of School Health, 79.1, 30 - 38.

Collier, D., \& Hebert, F. (2004): Undergraduate physical education teacher preparation: what practitioners tell us. Physical Educator, 61.2, $102-113$.

Condon, R., \& Collier, C.S. (2002): Student choice makes a difference in physical education. The Journal of Physical Education, Recreation and Dance, $73.2,26-31$.

Connor, B. (2009): What is a physical educator? The Journal of Physical Education, Recreation and Dance, 80.2, 6 - 8 .

Cozby, P. (2004): Methods in Behavioural Research. Eighth Edition. New York, McGraw-Hill.

Crotty, M. (1998): The Foundations of Social Research: Meaning and Perspective in the Research Process. Sydney, Allen \& Unwin.

Culpan, I. (2008): Physical Education and the New Zealand Curriculum: Maximising the Opportunity. New Zealand Physical Educator, 41.3, 51 - 63.

Daley, A.J., \& Ryan, J. (2000): Academic performance and participation in physical activity by secondary school adolescents. Perceptual and Motor Skills, 91.2, $531-535$.

Darst, P.W., Pangrazi, R., \& Stillwell, B. (1995): Middle school physical educationmake it more exciting!(Teaching tips). The Journal of Physical Education, Recreation and Dance, 66.8, 8 - 10 . 
Davidson, C., \& Tolich, M. (1999): Social science research in New Zealand: Many paths to understanding. Second Edition. Auckland, Pearson Education in New Zealand Limited.

Davis, K. (2003): Teaching for gender equity in physical education: A review of the Literature. Women in Sport \& Physical Activity Journal, 12, 2: 55.

English Encarta Dictionary Website: http://encarta.msn.com/ accessed on $4^{\text {th }}$ April 2009.

Ennis, C.D. (2008): Examining curricular coherence in an exemplary elementary school program. Research Quarterly for Exercise and Sport, 79.1, 71 - 85.

Esterhuizen, P.M. (1996): 'n Selfaktualiseringsbenadering tot Bestuurssukses binne ' $n$ Finansiele Instelling. (Doctoral Thesis, University of South Africa).

French, S.A., Perry, C.L., Leon, G.R., \& Jayne, A. (1996): Weight concerns, dieting behavior, and smoking initiation among adolescents: A prospective study. American Journal of Public Health, 84, 11: 1818 - 1820.

Gerrone, G.H. (2000): Characterization of preadolescent girls' body-image as revealed through a sentence completion instrument. Proquest Dissertations And Theses.

Gilbert, S. (1999): Fear of Being Fat; Why Young Women Are Prey to Eating Disorders. Washington, D.C., The Washington Post.

Greenberg, D.S. (1989): Fat anxiety starts at an early age - and it's no wonder. Chicago Tribune, $19^{\text {th }}$ June, Chicago, 3.

Greey, M. (2000): Fear of fat: why more and more young children are dieting. Today's Parent, 17, $10-114$.

Grierson, R.M. (2005): Does regular physical activity influence academic performance in incoming freshmen students at Delta State University? Proquest Dissertations and Theses, Mississippi Delta State University, 104 pages.

Griffin, A.C., Younger, K.M., \& Flynn, M.A.T. (2004): Assessment of obesity and fear of fatness among inner-city Dublin schoolchildren in a one-year followup study. Public Health Nutrition, 7.6, 729 - 735.

Guedes, C. (2007): Physical education and physical activity: A historical perspective. The Journal of Physical Education, Recreation \& Dance, 78.8, $31-32$ and $47-48$. 
Hallinan, M.T. (2008): Teacher influences on students' attachment to school. Sociology of Education, 81.3, 271 - 284.

Hamlin, M.J., \& Ross, J.J. (2005): Barriers to physical activity in young New Zealanders. Youth Studies Australia, 24.1, 31 - 38.

Hands, B., \& Martin, M. (2003): Fundamental movement skills: children's perspectives. Australian Journal of Early Childhood, 28.4, 47 - 53.

Headley, S. (2001): Exercise is positively related to adolescents' relationships and academics. Youth Studies Australia, 20.3, 63 - 66.

Headley, S. (2005): The good life: New Zealand children's perspectives on health and self. Youth Studies Australia, 24.1, 63 - 64.

Hellmich, N. (2006): More time in PE doesn't add up; Study finds that minutes actually spent moving are few. USA Today, $24^{\text {th }}$ August, United States of America, 8 .

Henninger, M., \& Coleman, M. (2008): De-escalation: How to take back control in your urban physical education classes. Strategies, 21.3, $11-15$.

Hill, G., \& Hannon, J.C. (2008): An analysis of middle school students physical education physical activity preferences. Physical Educator, 65.4, 180 - 195.

Hillier, A. (2008): Childhood overweight and the built environment: making technology part of the solution rather than part of the problem. Section One: Home, School, and Community. The Annals of the American Academy of Political and Social Science, 615, 56 - 83.

Hui, P. (2001): Schools may drop minority subjects. Falling Exam Numbers and Limited Resources threaten courses. South China Morning Post $11^{\text {th }}$ August, Hong Kong, 1.

Jenkins, J.M., Jenkins, P., Collums, A., \& Werhonig, G. (2006): Student perceptions of a conceptual physical education activity course. Physical Educator, 63.4, $210-222$.

Johnson, D.A. (2005): The effect of choice on motivation. The Journal of Physical Education, Recreation and Dance, 76.1, 8-9.

Johnson, R. (2008): Overcoming resistance to achievement-based unit grading in secondary physical education: should daily attendance, full participation, and good behaviour alone merit a passing grade in physical education? The Journal of Physical Education, Recreation \& Dance, 79.4, 46 - 50. 
Jutel, A. (2006): On cartwheels and other things. The Journal for Thematic Dialogue, 107 - 113.

Kahan, D. (2008): Recess, extracurricular activities, and active classrooms: means for increasing elementary school students' physical activity; physical education alone is not enough! The Journal of Physical Education, Recreation\& Dance, 79.2, 26 - 33.

Kirk, D., Macdonald, D., \& O’ Sullivan, M. (2006): The Handbook of Physical Education. London, Sage Publications.

Lee, A.M., Fredenburg, K., Belcher, D., \& Cleveland, N. (1999): Gender differences in children's conceptions of competence and motivation in physical education. Sport, Education and Society, 4, 2, 161 - 174.

Lipping, A. (2003): The platoon school curriculum and the diffusion of school physical education programs, 1900-1930, Socio-cultural aspects of physical activity. Research Quarterly for Exercise and Sport, 74.1, 71 - 72.

Macdonald, D. (2004): Curriculum change in health and physical education: The devil's perspective. Journal of Physical Education New Zealand, 37.1, 70 84.

Malina, R. M. (2001): Tracking of physical activity across the lifespan. President's Council on Physical Fitness and Sports Research Digest, 3, 14, 2 - 10.

McKenzie, T.L., Sallis, J.F., Faucette, N., Roby, J.J., \& Kolody, B. (1993): Effects of a curriculum and in-service program on the quantity and quality of elementary physical education classes. Research Quarterly for Exercise and Sport, 64.2, $178-188$.

McKenzie, T.L., \& Kahan, D. (2008): Physical activity, public health, and elementary schools. The Elementary School Journal, 108.3, 171 181.

Myerson, J. (2005): Not a games person. Great Britain, Yellow Jersey Press.

Nilges, L., \& Usnick, V. (2000): The role of spatial ability in physical education and mathematics. The Journal of Physical Education, Recreation and Dance, 71.6, 29.

Nixon, E.W., \& Cozens, F.W. (1952): An introduction to physical education. Fourth Edition, Philadelphia and London, W.B Saunders Company, 271 pages. 
Pagnano, K., \& Griffin, L. (2001): Making intentional choices in physical education. The Journal of Physical Education, Recreation and Dance, $72.5,38$.

Paterson, A., \& Hallberg, E.C. (1965): Background readings for physical education. United States of America, Holt, Rinehart and Winston Inc., 596 pages.

Petrie, K., Jones, A., \& McKim, A. (2007): Effective professional learning in physical activity. An evaluative research report in 2007 on the impact of effective professional learning in curricular and co-curricular physical activity in primary schools. Found on:

http://www.educationcounts.govt.nz/publications/schooling/25204/4 accessed on $22^{\text {nd }}$ October 2009.

Petrie, K. (2008): Physical education in primary schools: Holding on to the past or heading for a different future? New Zealand Physical Educator, 41.3, 67 82.

Pope, C. (2007): Happy $21^{\text {st }}$ birthday sport education: Where are we now? New Zealand Physical Educator, 40.2, 11 - 14.

Push Play Website: http://pushplay.sparc.org.nz accessed on $25^{\text {th }}$ March 2009.

Raviv, S., \& Low, M. (1990): Influence of physical activity on concentration among junior high-school students. Percept Mot Skills, 70.1, 67 - 74.

Rich, E., \& Evans, J. (2007): Re-reading voice: young women, anorexia and performative education. Junctures: The Journal for Thematic Dialogue, 9, $39-55$

Sallis, J.F., McKenzie, T.L., Kolody, B., Lewis, M., Marshall, S., \& Rosengard, P. (1999): Effects of health-related physical education on academic achievement: project SPARK. Research Quarterly for Exercise and Sport, $70.2,127-134$.

Sanders, C.E., Field, T.M., Diego, M., \& Kaplan, M. (2000): Moderate involvement in sports is related to lower depression levels among adolescents. Adolescence, 35, 793 - 797.

Schofield, G., Schofield, L., Dickson, G., \& Croteau, K. (2005): Sloth or gluttony: Understanding obesity in New Zealand youth. Youth Studies Australia, 24.1, $28-31$. 
Sherar, L.B., Esliger, D.W., Baxter-Jones, A.D.G., \& Tremblay, M.S. (2007): Age and gender differences in youth physical activity: Does physical maturity matter? Medicine and Science in Sports and Exercise. 39.5, 830835.

Shewfelt, L.D. (1991): Indices of eating problems in 10 to 15 year old girls: A developmental study. Proquest Dissertations And Theses, 345 pages.

Shimon, J.M. (2007): Activity choice and Title IX. The Journal of Physical Education, Recreation and Dance, 78.9, 3 - 6.

Siegel, D. (2008): Quantification of physical activity in middle school physical education. The Journal of Physical Education, Recreation \& Dance, 79.2, $51-53$.

Smith, C.A. (2004): Attitudes of middle school students. The Journal of Physical Education, Recreation and Dance, 75.3, 5 - 6.

Smith, P.S. (2005): Beyond games, gadgets and gimmicks: differentiating instruction across domains in physical education; "Avoid one-size-fits-all instruction" is a sound injunction, but how should teachers individualize instruction? The Journal of Physical Education, Recreation and Dance, 76.8, 38 - 46.

Sport and Recreation New Zealand (SPARC), Website: http://sparc.co.nz accessed on $25^{\text {th }}$ March 2009.

Statistical Package for Social Sciences (SPSS), Website: www.spss.com accessed on $13^{\text {th }}$ April 2009.

Stelzer, J. (2005): Promoting healthy lifestyles: prescriptions for physical educators. Attitude influences behaviour and few people are better situated than physical educators to encourage positive attitudes toward lifelong wellness. The Journal of Physical Education, Recreation and Dance, 76.4, 26 - 31.

Stevens, T.A., Yen, T., Stevenson, S.J., \& Lochbaum, M.R. (2008): The importance of physical activity and physical education in the prediction of academic achievement. Journal of Sport Behavior, 31, 4, 368 - 388.

Stothart, R.A. (1974): The Development of Physical Education in New Zealand. Auckland, Heinemann Educational Books, 62 pages.

Taras, H. (2005): Physical activity and student performance at school. Journal of School Health, 75.6, $214-219$.

Tremarche, P.V., Robinson, E.M., \& Graham, L.B. (2007): Physical education and its effect on elementary testing results. Physical Educator, 64.2, $58-65$. 
Virgilio, S.J. (2009): The comprehensive approach to physical activity. The Journal of Physical Education, Recreation and Dance, 80.1, 5 - 8.

Williams, N.F., \& Germain, J. (2008): Fitness in disguise: fitness activities can actually be enjoyed rather than endured. The Journal of Physical Education, Recreation and Dance, 79.7, 35 - 41.

Wills, W., Backett-Milburn, K., Gregory, S., \& Lawton, J. (2006): Young teenagers' perceptions of their own and others' bodies: a qualitative study of obese, overweight and 'normal' weight young people in Scotland. Social Science and Medicine, 62.2, 396 - 407.

Wilson, R.D. (2003): Use videos to grab boys' attention. Teacher Librarian, 30.3, $51-52$.

Wright, J., Macdonald, D., \& Burrows, L. (2004): Critical Inquiry and problemsolving in physical education. USA \& Canada, Routledge.

Yu, C.C.W., Chan, S., Cheng, F., Sung, R.Y.T., \& Hau, K.T. (2006): Are physical activity and academic performance compatible? Academic achievement, conduct, physical activity and self esteem of Hong Kong Chinese primary school children. Educational Studies, 32, 4, 331. 


\title{
Appendix 1: Information sheet to School Principal
}

\author{
VICTORIA UNIVERSITY OF WELLINGTON \\ Te Whare Wananga o te Upoko o te Ika a Maui
}

\begin{abstract}
Attention: (name of principal)
Information Sheet for Exploring the Intermediate School Students' perceptions with regards to their experiences of their Physical Education Classes
\end{abstract}

Researcher: Michelle Esterhuizen, School of Social and Cultural Studies, Victoria University of Wellington

I am a Masters student in Social Science Research at Victoria University of Wellington. As part of this degree I am undertaking a research project leading to a thesis. This study is designed to determine the students' perceptions regarding their Physical Education classes presented at your school. It will aim at finding out whether the students feel that their Physical Education classes contribute to their overall physical wellbeing. In addition the information will also be used to determine whether the students feel that their Physical Education classes are beneficial not only to their health but also to their academic performance. The findings of this research will provide the school with information on exactly how their students feel about the quality of the Physical Education classes presented there and whether it needs to be reviewed for future references. This will be done by means of a simple questionnaire that the students will be asked to complete. The four page questionnaire will take approximately 10 to 15 minutes to complete. As per University requirements, ethical approval had been obtained for this particular research project.

It was my intention to notify both the students and their parents/caregivers about the research via the school newsletter. If a parent or student wishes not to partake in the study they will need to notify the school before the day of administration of the questionnaires, otherwise consent will be assumed. Participation is completely voluntary and all responses will be anonymous. The school's name will not be mentioned in the research.

Responses collected will form the basis of my research project and the results will be put into a written report. All material collected will be kept confidential. No other person besides me and my supervisor, Dr Jenny Neale, will see the questionnaires. The thesis will be submitted for marking to the School of Social and Cultural Studies and deposited in the University Library. It is intended that one or more articles will be submitted for publication in scholarly journals.

If you have any questions or would like to receive further information about the project, please contact me on my mobile number: XXXXX or my supervisor, Dr Jenny Neale, at the School of Social and Cultural Studies at Victoria University, P O Box 600, Wellington.

Michelle Esterhuizen

Thank you for your time 


\title{
Appendix 2: The Questionnaire
}

\author{
VICTORIA UNIVERSITY OF WELLINGTON \\ Te Whare Wananga o te Upoko o te Ika a Maui
}

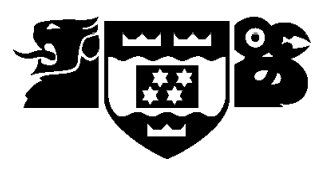

Thank you for taking the time to complete this survey!

Please answer all questions honestly. Remember there are no right or wrong answers to any of these questions, just put down how you feel.

Please circle your chosen response

Question 1: How much do you like doing P. E. at school?

$\begin{array}{crrc}1 & 2 & 3 & 4 \\ \text { Really Like } & \text { Like } & \text { Dislike } & \text { Really dislike }\end{array}$

Question 2: How well do you think you are at doing P. E.?

$\begin{array}{lllll}1 & 2 & 3 & 4 & 5\end{array}$

Very well Well Average Poor Very poor

Question 3: Do you have a choice in the type of activities you do when you have P. E.?

Yes

No

Sometimes 
Question 4: How do you feel about doing activities in P. E. you haven't tried before?

1

I like it
2

I don't mind

Question 5: Would you like to do more P. E. at school?

Yes

No

Question 6: Why is this?

Question 7: How much do you think P. E. helps you in other areas of your life?

1 2

3 4

A lot Somewhat Not much Not at all

Question 8: How much do you like doing exercise in your own time (not at school)?

$\begin{array}{llll}1 & 2 & 3 & 4\end{array}$

A lot Somewhat Not much Not at all

Question 9: Do you want to keep doing P. E. when you are older?

Yes

No 
Question 10: Why is this?

Question 11: Do you feel you learn enough about health in your PE class?

Yes

No

Question 12: Do you think learning about health is useful to you?

Yes

No

Question 13: How much do you think being fit will help you with your school marks?

$\begin{array}{llll}1 & 2 & 3 & 4\end{array}$

A lot Somewhat Not much Not at all

Question 14: How well do you do at school?

1

2

3

4

5

Very well Well Average Not well Not well at all

Question 15: How much do you like coming to school?

$\begin{array}{llll}1 & 2 & 3 & 4\end{array}$

A lot Somewhat Not much Not at all 
Question 16: Please add any other comments about doing PE at your school

And now some questions about you:

What is your favourite subject at school?

Why is this your favourite subject?

How old are you?

Are you: Male

Female

Ethnic Group: NZ European

Māori

Pacific Islander

Asian

South African

English

Other

Thank you very much for taking the time to fill out this questionnaire! Have a nice day ( 


\section{Appendix 3: Insert in School Newsletter}

\section{Thesis Research re. PE}

Michelle Esterhuizen is a Masters Student form Victoria University, Wellington. She is interested in conducting her thesis research with and for our school. This will involve all of the students at (schools' name) whereby each student will be asked to complete a simple questionnaire. This will take place on Thursday, $14^{\text {th }}$ August. The questionnaire will ask the students what their perceptions are about their experiences of the physical education classes here at school. This will take approximately $10-15$ minutes to complete and this will be done during class time. Your children will not be asked to put their names on the questionnaires and the name of the school will not be used in her published thesis project. If you do not want your child to participate in this research, please let the school know before Monday $11^{\text {th }}$ August 2008.

You can contact Michelle directly if you require more information. (Contact details provided) 


\section{Appendix 4: Results in Table Format}

Table 2: Age of Participants

\begin{tabular}{|c|c|c|}
\hline Age Groups & Frequency & Percentage \\
\hline 11 & 104 & 31.0 \\
\hline 12 & 152 & 45.2 \\
\hline 13 & 71 & 21.1 \\
\hline Missing & 9 & 2.7 \\
\hline Total & 336 & 100 \\
\hline
\end{tabular}

Table 3: Ethnicity of Participants

\begin{tabular}{|c|c|c|}
\hline Ethnic Group & Frequency & Percentage \\
\hline $\begin{array}{c}\text { New Zealand } \\
\text { European }\end{array}$ & 236 & 70.2 \\
\hline Māori & & \\
\hline Pacific Islander & 2 & 9.5 \\
\hline Asian & 1 & 0.6 \\
\hline British & 8 & 0.3 \\
\hline South African & 24 & 7.1 \\
\hline Other & 12 & 2.4 \\
\hline Multiple & 20 & 3.6 \\
\hline Missing & 1 & 6.0 \\
\hline Total & 336 & 0.3 \\
\hline
\end{tabular}

Table 4: Quantity of PE

\begin{tabular}{|c|c|c|}
$\begin{array}{c}\text { Would you like to do } \\
\text { more PE at school? }\end{array}$ & Male & Female \\
\hline Yes & $91 \%$ & $87 \%$ \\
\hline No & $9 \%$ & $13 \%$ \\
\hline
\end{tabular}


Table 5: Level of Choice

Do you have a choice in the types of activities you do when you have PE?

Yes

Sometimes

$82 \%$

No

$13 \%$

$87 \%$

$11 \%$

Table 6: Fitness and Academic Performance

\section{How much do you think being fit will help you with your school marks?}

A lot

Somewhat

Not Much

Not at All

Male

$35 \%$

$49 \%$

$15 \%$

$1 \%$

\section{Female}

$36 \%$

$45 \%$

$19 \%$

$0.6 \%$

Table 7: Range of Activities

Need more types of

Activities

\section{Male}

$11 \%$
Female

$23 \%$

Table 8: Fear of Fatness

\begin{tabular}{|c|c|c|}
\hline Ethnicity & Male & Female \\
\hline NZ European & $11 \%$ & $14 \%$ \\
\hline Māori & $0 \%$ & $2 \%$ \\
\hline British & $0.6 \%$ & $1.2 \%$ \\
\hline Other & $0 \%$ & $0.6 \%$ \\
\hline Multiple & $0 \%$ & $0.6 \%$ \\
\hline
\end{tabular}

